\title{
An official American Thoracic Society/ European Respiratory Society statement: research questions in COPD
}

\author{
Bartolome R. Celli ${ }^{1}$, Marc Decramer ${ }^{1}$, Jadwiga A. Wedzicha ${ }^{1}$, Kevin C. Wilson ${ }^{1}$, \\ Alvar Agustí, Gerard J. Criner, William MacNee, Barry J. Make, \\ Stephen I. Rennard, Robert A. Stockley, Claus Vogelmeier, Antonio Anzueto, \\ David H. Au, Peter J. Barnes, Pierre-Regis Burgel, Peter M. Calverley, \\ Ciro Casanova, Enrico M. Clini, Christopher B. Cooper, Harvey O. Coxson, \\ Daniel J. Dusser, Leonardo M. Fabbri, Bonnie Fahy, Gary T. Ferguson, \\ Andrew Fisher, Monica J. Fletcher, Maurice Hayot, John R. Hurst, \\ Paul W. Jones, Donald A. Mahler, François Maltais, David M. Mannino, \\ Fernando J. Martinez, Marc Miravitlles, Paula M. Meek, Alberto Papi, \\ Klaus F. Rabe, Nicolas Roche, Frank C. Sciurba, Sanjay Sethi, Nikos Siafakas, \\ Don D. Sin, Joan B. Soriano, James K. Stoller, Donald P. Tashkin, \\ Thierry Troosters, Geert M. Verleden, Johny Verschakelen, Jorgen Vestbo, \\ John W. Walsh, George R. Washko, Robert A. Wise, Emiel F.M. Wouters and \\ Richard L. ZuWallack, on behalf of the ATS/ERS Task Force for COPD Research
}

Further details of this ATS/ERS Task Force for COPD Research can be found in the acknowledgements section. ${ }^{1}$ Project co-chairs; should be considered co-first authors.

Correspondence: Kevin C. Wilson, Senior Director, Documents and Medical Affairs, American Thoracic Society. c/o The Pulmonary Center, R-304, 72 E. Concord Street, Boston University Medical Center, Boston, MA 02118, USA. E-mail: kwilsonathoracic.org

ABSTRACT Chronic obstructive pulmonary disease (COPD) is a leading cause of morbidity, mortality, and resource use worldwide. The goal of this official American Thoracic Society (ATS)/European Respiratory Society (ERS) research statement is to describe evidence related to diagnosis, assessment and management; identify gaps in knowledge; and make recommendations for future research. It is not intended to provide clinical practice recommendations on COPD diagnosis and management.

Clinicians, researchers, and patient advocates with expertise in COPD were invited to participate. A literature search of Medline was performed, and studies deemed relevant were selected. The search was not a systematic review of the evidence. Existing evidence was appraised and summarised, and then salient knowledge gaps were identified.

Recommendations for research that addresses important gaps in the evidence in all areas of COPD were formulated via discussion and consensus.

Great strides have been made in the diagnosis, assessment and management of COPD, as well as understanding its pathogenesis. Despite this, many important questions remain unanswered. This ATS/ ERS research statement highlights the types of research that leading clinicians, researchers, and patient advocates believe will have the greatest impact on patient-centred outcomes.

@ERSpublications

ATS/ERS statement: which types of research will have the greatest future impact on patientcentred outcomes in COPD? http://ow.ly/I54Hb

This official statement of the American Thoracic Society (ATS) and the European Respiratory Society (ERS) was approved by the ATS Board of Directors, November 25, 2014, and by the ERS Science Council and Executive Committee, November 5 and November 27, 2014, respectively.

This statement is also published in the American Journal of Respiratory and Critical Care Medicine 2015 [DOI: 10.1164/ rccm.201501-0044ST]; the executive summary is also published in the European Respiratory Review 2015; 24: 159-172.

Conflict of interest: Disclosures can be found alongside the online version of this article at erj.ersjournals.com

Copyright $\odot$ ATS/ERS 2015 


\section{Introduction}

Chronic obstructive pulmonary disease (COPD) is a leading cause of morbidity and mortality. Global Burden of Disease studies have estimated that COPD is the third leading cause of death worldwide [1] and in the USA [2]. Mortality appears to be decreasing worldwide [3]; despite this, COPD still caused more than 3 million deaths in 2010 alone [1]. It is also the second leading cause of disability-adjusted life-years lost [4]. COPD-related mortality more than doubled among women over a 20-year observation period [5], and exacerbations now account for $50 \%$ to $75 \%$ of the costs associated with COPD [6].

Given the 10-year interval since publication of the official American Thoracic Society (ATS)/European Respiratory Society (ERS) standards for the diagnosis and treatment of patients with COPD [7], leaders of the societies felt a need to summarise evidence related to the diagnosis, assessment, and management of COPD; identify knowledge gaps and research questions; and make recommendations for future research. Clinical information from the ATS/ERS standards [7] is included as context for discussion, but this research statement is not intended to be a clinical practice guideline, because other documents are available that provide specific clinical recommendations for the diagnosis and management of stable COPD $[8,9]$. Clinical recommendations related to COPD exacerbations are similarly not provided because there is a forthcoming ATS/ERS clinical practice guideline that specifically addresses the topic.

\section{Methods}

Committee composition

Each society selected two co-chairs on the basis of their expertise in COPD and/or group facilitation. The co-chairs invited individuals to participate in the project on the basis of their expertise in research or clinical aspects of COPD. The participants were then divided into seven groups, a leader was chosen for each group, and topics were assigned to each group.

\section{Literature search and evidence appraisal}

One of the co-chairs performed a literature search of Medline for each topic. The results of the searches were sent to the groups, who reviewed and selected the studies that they deemed relevant to their topic. Group members were allowed to supplement the literature search with their own searches and to identify relevant studies from other sources. The literature search conducted for this research statement was not a systematic review of the evidence.

\section{Research recommendations}

Each group appraised and summarised the existing evidence and then identified salient knowledge gaps. Preliminary research recommendations were formulated to address these gaps. The recommendations were formulated via discussion and consensus. Guideline methodology was not used to formulate or grade the recommendations because they are research recommendations and not patient care recommendations.

\section{Document development}

Group leaders sent drafts to either the diagnosis (B.R. Celli) or treatment (M. Decramer) co-chair, who collated and edited the contributions from the groups. The diagnosis and treatment drafts were then sent to the remaining co-chairs (J.A. Wedzicha and K.C. Wilson), who collated and edited the drafts into a single document. The final draft was sent to all participants for review and feedback, including patient advocates and representatives. Multiple cycles of revision, review and feedback followed until all participants agreed on a version of the draft.

\section{Definitions}

\section{COPD}

The ATS and ERS define COPD as a preventable and treatable disease state characterised by airflow limitation that is not fully reversible [7]. The airflow limitation is usually progressive and associated with a chronic inflammatory response of the lungs to noxious particles or gases. Cigarette smoking is the most common risk factor for COPD [10], but others are increasingly being recognised (e.g. biomass fuels and $\alpha_{1}$-antitrypsin deficiency). Dyspnoea and exacerbations represent the most prominent respiratory manifestations of COPD. In most patients, COPD represents the pulmonary component of a chronic multimorbidity. It is particularly common among the elderly and associated with many common risk factors, such as smoking, pollution, ageing, inactivity and diet [11].

\section{Outcomes}

Outcomes are the results of an intervention. Traditionally, many outcomes measured in COPD research have been physiological, such as lung function (e.g. forced expiratory volume in $1 \mathrm{~s} ; \mathrm{FEV} 1$ ) or functional capacity (e.g. 6-min walk distance). Physiological outcomes are desirable because they are readily measured, provide 
information about disease progression, and are related to clinical outcomes such as mortality and exacerbations. Anatomical outcomes have also been used in studies of COPD, such as histological or imaging findings. Physiological and anatomical outcomes make research easier, more efficient, and less costly.

There is increasing recognition, however, that the relationship between many surrogate outcomes (i.e. physiological and/or anatomical outcomes) and outcomes that matter to patients (i.e. "patient-centred" or "patient-important" outcomes, such as dyspnoea, quality of life, frequency of exacerbations, frequency of hospitalisations, and mortality) is modest at best, and interventions that improve surrogate outcomes frequently do not affect patient-centred outcomes. As a result, there is increasing emphasis on 1) using patient-centred outcomes in clinical research, and 2) finding high-quality surrogate outcomes that reliably predict patient-centred outcomes [12].

We recommend:

- Studies that determine which outcomes matter most to patients with COPD and, therefore, are truly patient-centred outcomes in this population.

- Studies that correlate physiological and anatomical outcomes with patient-centred outcomes, to identify high-quality surrogate outcomes that may be used in future research.

- Preferential use of patient-centred outcomes to inform judgments related to patient care until surrogate outcomes have been identified that strongly correlate with patient-centred outcomes.

\section{Clinical presentation and initial assessment}

The diagnosis of COPD is first suspected when a patient 1) complains of a cough, sputum production, dyspnoea or recurrent lower respiratory infections [13]; 2) reports risk factors for the disease, such as exposure to cigarette smoke or environmental or occupational pollutants; or 3) presents with an acute exacerbation. Additional medical history is then obtained to assess for each of the following: further evidence that COPD is present, evidence that an alternative disease is not the cause of the symptoms, evidence that comorbidities are present, the ability to perform activities of daily living, other effects of the condition, and the availability of social support [7].

The purpose of the physical examination is to identify respiratory and systemic effects of COPD. A normal physical examination is common in mild COPD, with signs becoming apparent as the disease progresses. Examples include quiet breath sounds, a prolonged expiratory duration, signs of hyperinflation of the lungs, cyanosis and weight loss. Detection of diminished breath sounds and hyperresonance have a positive likelihood ratio of greater than 5.0, meaning that the combination of findings is a moderately strong predictor that COPD is present. In addition, the respiratory rate, oxygen saturation at rest and with exertion, weight, height, body mass index (BMI), breathlessness (using the modified Medical Research Council dyspnoea score; mMRC) and functional capacity are routinely measured. Functional capacity is best determined by an exercise test, such as timed walking distances or walking speed. Exercise tests have been shown to predict mortality particularly well in patients with COPD [14].

Chest radiography is generally performed during the initial diagnostic evaluation of patients with suspected COPD to exclude other diseases that may cause similar symptoms and signs (table 1) and to establish the presence of concomitant respiratory diseases. It is frequently normal in early COPD. The radiographic changes associated with COPD include lung hyperinflation and hyperlucent areas in the lungs with peripheral trimming of vascular markings. Chest radiography is not performed during routine follow-up of a stable patient with COPD.

Computed tomography (CT) can estimate the degree of emphysema and its distribution, and identify bronchial wall thickening and gas trapping. These estimates correlate with lung function abnormalities, but there are substantial variations among those interpreting the studies, particularly when features are subtle $[15,16]$. To mitigate interpreter variability, numerous quantitative techniques have been applied $[17,18]$. These techniques have not become routine clinical practice, however, due to the complex and time-consuming nature of the quantitative analysis (with the exception of emphysema), differences in the algorithms used by equipment manufacturers, the need for specialised software, the requirement of meticulous segmentation and analysis of airways, the lack of a standardised CT protocol to assess emphysema, and the lack of agreement on complex measurements (e.g. airway wall dimensions) [19-22].

Additional advantages of CT scanning are that it can help differentiate between structural abnormalities that cause airflow limitation (e.g. emphysema, bronchiolitis and bronchiectasis), identify abnormalities that are associated with clinically significant features (i.e. phenotypes), and detect both pulmonary comorbidities (e.g. lung cancer, interstitial lung disease and pulmonary hypertension) and nonpulmonary comorbidities (e.g. coronary artery calcifications, heart failure and diseases of the mediastinum) [23]. The risk of lung cancer is increased among patients with COPD, but it is inversely related to the degree of airflow obstruction [24]. The presence of airflow obstruction should raise awareness of the risk for lung cancer; indeed, patients 
TABLE 1 Differential diagnosis of chronic obstructive pulmonary disease (COPD)

\section{Diagnosis}

COPD

Congestive heart failure

Bronchiectasis

Tuberculosis

Obliterative bronchiolitis

Diffuse panbronchiolitis

\section{Suggestive features}

Mid-life onset

Slowly progressing symptoms

Long history of smoking

Early onset

Varying symptoms

Symptoms during the night/early morning

Presence of allergy, rhinitis and/or eczema

A family history

Airflow limitation that is largely reversible

Fine basilar crackles on auscultation

Dilated heart on chest radiography

Peripheral oedema

History of ischaemic heart disease

Volume restriction not airflow limitation on pulmonary function tests

Large volume of purulent sputum

Commonly associated with bacterial infection

Coarse crackles on auscultation

Clubbing

Bronchial dilation and bronchial wall thickening on chest radiography/CT

Onset at all ages

Lung infiltrate on chest radiography

Microbiological confirmation

High local prevalence of tuberculosis

Younger onset and in nonsmokers

History of rheumatoid arthritis/fume exposure?

Hypodense areas on expiration on CT

Affects mostly male nonsmokers

Almost all have chronic sinusitis

Diffuse small centrilobular nodular opacities and hyperinflation on chest radiography and HRCT

CT: computed tomography; HRCT: high-resolution computed tomography.

with COPD are considered good candidates to be screened for lung cancer, especially if they have radiological emphysema or a low diffusion capacity for carbon monoxide (DLCO) [24].

We recommend:

- Studies to determine whether there is a role for routine CT scanning among patients with newly diagnosed COPD.

- Studies to identify CT findings that reliably and consistently correlate airway dimension measurements with lung function, using pulmonary function tests as the reference standard.

- Studies to identify CT findings that are associated with clinically significant features (i.e. phenotypes) and differential responses to treatment.

- Studies to determine the optimal CT protocol and quantification methods. The results may allow CT scans performed using different types of CT scanners to be compared with one another, which would facilitate longitudinal assessment, multicentre trials, and multicentre clinical care.

\section{Diagnosis}

Diagnosis of COPD requires confirmation of an airflow limitation that is not fully reversible via spirometry and the history of a potentially causative exposure (e.g. smoking). Airflow limitation that is not fully reversible is defined by a low post-bronchodilator $\mathrm{FEV} 1$ /forced vital capacity (FVC) ratio [7].

The threshold FEV1/FVC ratio that should be used to confirm an airflow limitation is uncertain. A post-bronchodilator FEV1/FVC ratio of less than 0.7 has traditionally been the criterion for airflow limitation [7, 8]. This threshold may result in more frequent identification of airflow limitation and, hence, diagnosis of 
COPD among the elderly [25] and less frequent diagnosis among young adults $<45$ years of age [26], compared with a threshold based on the lower limit of normal (LLN) of FEV1/FVC. Although these observations are particularly relevant for epidemiological studies, advocates for the fixed ratio argue that it identifies a number of patients with significant pulmonary pathology and respiratory morbidity not detected by the LLN [27], and advocates for the LLN argue that the fixed ratio is more likely to yield false-positive results [25].

Screening asymptomatic individuals for COPD using spirometry is controversial. There is evidence that screening detects undiagnosed COPD [28]. However, asymptomatic individuals with mild airflow limitation (Global Initiative for Chronic Obstructive Lung Disease (GOLD) grade 1) may not have faster lung function decline or a lower quality of life than asymptomatic individuals with normal lung function [29], and there are no data showing that outcomes improve among individuals who are identified as having COPD before developing symptoms, that early treatment provides any benefit in asymptomatic individuals, or that screening is cost-effective [30].

We recommend:

- Studies that measure the accuracy of various tools (e.g. questionnaires) to detect symptoms in patients at risk for COPD, using spirometry as the reference standard.

- Studies that compare outcomes among individuals diagnosed with COPD on the basis of an FEV1/FVC ratio less than 0.70 with those among individuals diagnosed with COPD on the basis of an FEV1/FVC below the LLN.

- Studies that compare outcomes among symptomatic individuals whose COPD diagnosis is based on the combination of an airflow limitation confirmed by spirometry and a history of exposure to the causative agent with those among symptomatic individuals whose COPD diagnosis has not been confirmed with spirometry, but rather is based on an alternative approach. Examples of alternative approaches include various combinations of symptoms, imaging findings, and physiological abnormalities measured by complementary tests, such as forced oscillation techniques.

- Studies that evaluate case-finding strategies using questionnaires, mini-spirometers, and office spirometry in areas where access to conventional spirometry requires specialised assessment.

- Studies that examine the impact of ascertainment (e.g. by spirometric screening versus spirometry performed due to symptoms and an exposure history) on medium- and long-term outcomes in individuals with COPD.

- Studies that evaluate the impact of age on the importance of identifying an airflow limitation (i.e. is it more important to identify asymptomatic airflow limitation in a 30-year-old than an 80-year-old?).

\section{Assessment after diagnosis \\ Disease severity}

The severity of a disease relates to the extent of functional impairment of the target organ(s). Classification of COPD severity by spirometry alone (table 2) predicts patient-centred outcomes, such as health status [31], use of healthcare resources [32], frequency of exacerbations [33, 34] and mortality [35]. However, this approach is primarily intended for populations [36] and is not a substitute for clinical judgment in the evaluation of the severity of disease in individual patients.

The BMI and functional dyspnoea (i.e. dyspnoea that affects functional ability, employment, quality of life or health status [37]) also predict patient-centred outcomes. The BMI is obtained by dividing the weight $(\mathrm{kg})$ by the square of the height $\left(\mathrm{m}^{2}\right)$; values $<21 \mathrm{~kg} \cdot \mathrm{m}^{-2}$ are associated with increased mortality [38, 39]. The severity of functional dyspnoea can be assessed using the mMRC (table 3) [40]. Increased mMRC levels of dyspnoea are associated with increased mortality [41]. Exacerbation frequency, health status and level of physical activity are also predictors of mortality [42].

TABLE 2 Spirometric classification of the severity of chronic obstructive pulmonary disease (COPD)

Severity of obstruction

Post-bronchodilator FEV 1 /FVC

FEV $1 \%$ pred

\begin{tabular}{lcc}
\hline At risk & $>0.7$ & $\geqslant 80$ \\
Mild COPD & $\leqslant 0.7$ & 780 \\
Moderate COPD & $\leqslant 0.7$ & $50-80$ \\
Severe COPD & $\leqslant 0.7$ & $30-50$ \\
Very severe COPD & $\leqslant 0.7$ & $<30$ \\
\hline
\end{tabular}

FEV1: forced expiratory volume in $1 \mathrm{~s}$; FVC: forced vital capacity. At risk are 1) patients who smoke or have exposure to pollutants, 2) patients who have cough, sputum, or dyspnoea and 3) patients who have a family history of chronic respiratory disease. 


\begin{tabular}{|c|c|}
\hline Grade & Description \\
\hline 0 & Not troubled with breathlessness, except during strenuous exercise \\
\hline 1 & Troubled by shortness of breath when hurrying or walking up a slight hill \\
\hline 2 & $\begin{array}{l}\text { Walks slower than people of the same age due to breathlessness or has to stop for breath when } \\
\text { walking at own pace on a level surface }\end{array}$ \\
\hline 3 & Stops for breath after walking about $100 \mathrm{~m}$ or after a few minutes on a level surface \\
\hline 4 & Too breathless to leave the house or breathless when dressing or undressing \\
\hline
\end{tabular}

Several composite indices of disease severity have been developed (table 4) [43-50]. Although the prognostic accuracy of each of these indices has been confirmed in separate studies, few studies have directly compared one index to another. The GOLD Global Strategy for the Diagnosis, Management, and Prevention of COPD [8] proposed a multidimensional assessment of COPD for the purposes of treatment selection. The assessment includes: 1) high/low symptoms using the mMRC dyspnoea scores, the COPD Assessment Test, or the clinical COPD questionnaire; 2) the severity of airflow limitation; and 3) the number of yearly exacerbations. Patients with high symptom scores (mMRC dyspnoea score $\geqslant 2$, COPD Assessment Test score $\geqslant 10$, or clinical COPD questionnaire score $\geqslant 1$ ) and GOLD grade 3 or 4 spirometry and/or frequent exacerbations (two or more exacerbations in the preceding year and/or one hospitalisation) are considered at high risk for further exacerbations and, indirectly, poor clinical outcomes. The proposed approach has not yet been fully validated and is the subject of current research [51-53].

Concomitant chronic diseases may contribute to the severity of disease in patients with COPD, and inclusion of comorbidities in the multidimensional evaluation of patients with COPD is useful in the context of comprehensively evaluating patients with COPD [50, 54].

We recommend:

- Studies that determine which index or indices best stratify patients for the purpose of determining disease severity or recommending treatment.

- Studies that determine if short-term changes in these indices or other measures (e.g. lung function, CT findings and biomarkers) are useful surrogate markers of medium- or long-term patient-centred outcomes, thus shortening the time needed to complete therapeutic trials.

- Studies that contribute to a better understanding of the pathogenesis, impact, prevention and treatment of concomitant diseases in patients with COPD.

\section{Disease activity}

Activity of a disease relates to the level of activation of the biological processes that drive disease progression. Disease activity is a different concept than disease severity. In theory, identifying and treating active pathological processes may mitigate or eliminate disease progression.

\section{TABLE 4 Composite prognostic indexes in chronic obstructive pulmonary disease}

\begin{tabular}{llc} 
Composite index & Components & Reference \\
\hline BODE & BMI, FEV1, mMRC, 6MWD & {$[43]$} \\
mBODE & $B M I, F E V 1, m M R C$, peak V' ${ }_{2}$ & {$[44]$} \\
eBODE & $B M I, F E V 1, m M R C, 6 M W D$, exacerbation rate & {$[45]$} \\
BODEx & $B M I, F E V 1, m M R C$, exacerbation rate & {$[46]$} \\
Inflammatory BODE & BODE, inflammatory biomarkers, age, and hospitalisation history & {$[47]$} \\
ADO & Age, mMRC, FEV1 & {$[48]$} \\
DOSE & mMRC, FEV1, smoking status, exacerbation rate & {$[49]$} \\
CODEx & Comorbidity, obstruction, dyspnoea, and previous severe exacerbations & {$[50]$}
\end{tabular}

BODE: body mass index, airflow obstruction, dyspnoea and exercise capacity index; BMI: body mass index $\left(\mathrm{kg} \cdot \mathrm{m}^{-2}\right)$; FEV 1 : forced expiratory volume in $1 \mathrm{~s}$ (severity of airflow limitation, \% predicted); mMRC: modified Medical Research Council dyspnoea score; 6MWD: 6-min walk distance; mBODE: modified BODE in which 6MWD is replaced by peak oxygen consumption; eBODE: exacerbations added to original BODE; BODEx: exacerbations replace 6MWD in the original BODE; inflammatory BODE: inflammatory markers added to original BODE; ADO: age, dyspnoea and airflow obstruction index; DOSE: dyspnoea, airflow obstruction, smoking status and exacerbations index; CODEx: comorbidities, airflow obstruction, dyspnoea and exacerbations index; peak $\mathrm{V}^{\prime} \mathrm{O}_{2}$ : peak exercise oxygen consumption $\left(\mathrm{mL} \cdot \mathrm{min}^{-1}\right)$. 
The biological processes that drive disease progression in COPD are likely to be related to the balance between the pulmonary and systemic inflammatory responses to inhalational injury and the subsequent repair process [55]. It is unclear how to measure the activity of these processes. Potential surrogate markers include the rate of change of clinical markers of disease progression, because faster rates of disease progression presumably indicate more disease activity. Examples of clinical markers include worsening dyspnoea and health status, loss of exercise capacity, cough and sputum production, active smoking, appearance or worsening of comorbidities, weight loss, and frequency of exacerbations [56, 57]. Other measures can be categorised as functional markers (e.g. FEV1 decline, deterioration of DLCO and progressive hyperinflation), structural markers (e.g. progression of emphysema, worsening of airway dimensions, and appearance or worsening of bronchiectasis), and biological markers (e.g. biological markers in the lung, circulating blood, exhaled air, and/or urine).

Disease progression in established COPD is heterogeneous [58], ranging from rapid progression to stable or even improved lung function. This suggests that disease activity is also variable.

We recommend:

- Studies that relate potential biomarkers of disease activity (e.g. rate of lung function decline, increased exacerbation frequency, inflammation, lung tissue destruction, and repair responses induced by inhalational injury) to patient-centred outcomes to validate the biomarkers as clinically useful measures of disease activity.

- Studies that evaluate the impact of disease activity on treatment response and, conversely, the effects of treatment on disease activity.

\section{Phenotyping}

A phenotype is the observable properties (i.e. phenotypic traits) of an organism, which are determined by its genotype and modulated by its environment [59]. Some phenotypes influence the clinical course of COPD. A clinical COPD phenotype has been defined as "A single or combination of disease attributes that describe differences between individuals with COPD as they relate to clinically meaningful outcomes (e.g. symptoms, exacerbations, response to therapy, rate of disease progression, or death)" [60].

Clinical phenotyping may be complicated for several reasons. First, the presentation of some clinical phenotypes may change due to the effect of therapy and/or the natural course of the disease. Secondly, although a COPD phenotype describes differences between individuals with COPD, a given patient can have more than one clinical phenotype. Finally, two prevalent diseases can coexist (e.g. COPD and obstructive sleep apnoea, or COPD and asthma).

Only a few COPD phenotypes have been validated. They include $\alpha_{1}$-antitrypsin deficiency, frequent (two or more per year) exacerbations, chronic bronchitis, and upper lobe emphysema with poor exercise tolerance after rehabilitation in patients with severe airflow limitation. Other COPD phenotypes have been proposed, but still require validation confirming their relationship with clinically meaningful outcomes: severe hypoxaemia, disproportionate symptoms, persistent systemic inflammation, chronic airway bacterial colonisation, emphysema predominance with pulmonary hyperinflation and lung cancer, the asthma/ COPD overlap syndrome, premature or early severe airflow limitation ( $<55$ years), out-of-proportion pulmonary hypertension (mean pulmonary arterial pressure $<40 \mathrm{mmHg}$ ), COPD in never smokers, and the four new patient types (i.e. types A, B, C and D) proposed by GOLD [8]. Even if some of these phenotypes are associated with clinically meaningful outcomes, many experts believe that research should focus on those phenotypes where outcomes can be modified with therapy. In fact, exploratory therapeutic interventions in targeted populations are performed for the validation of a clinical phenotype.

We recommend:

- Studies to relate potential phenotypic traits with outcomes. Such evidence may provide more individualised prognostic information.

- Studies to relate potential phenotypic traits with response to therapy. Such evidence may identify specific types of patients who are more or less likely to respond to a given therapy, facilitate the development of personalised medicine, and increase the priority of future research studies that plan to enrol phenotypes whose outcomes can be potentially modified by therapy.

- Studies to enhance understanding of the treatment impact of various COPD phenotypes (e.g. asthma/ COPD overlap, $\alpha_{1}$-antitrypsin deficiency and bronchiectasis).

\section{Comorbidities}

COPD is frequently associated with one or more comorbidities and/or systemic effects. Therefore, in many patients, COPD can be considered just the pulmonary component of the multimorbidity that is characterised by concomitant chronic diseases (e.g. hypertension, atherosclerosis, chronic heart failure, lung cancer, 
osteoporosis and depression) and systemic effects (e.g. weight loss, muscle weakness) that are not fully explained by ageing and other common risk factors (e.g. smoking, diet, inactivity and lifestyle) [61-63]. Chronic comorbidities are prominent contributors to the clinical severity of patients with COPD, as they often affect important patient-centred outcomes.

Ischaemic heart disease is a particularly common comorbidity, contributing to worsening health and functional status [64], increased risk of a longer exacerbation [64], more dyspnoea [64] and decreased survival [65]. COPD is also associated with an increased incidence of lung cancer [24, 66] and prevalence of diabetes, hypertension, and other cardiovascular diseases, even after controlling for tobacco smoking in some studies. The Toward a Revolution in the treatment of Chronic obstruction (TORCH) trial enrolled patients with moderate to severe airflow limitation and demonstrated that $26 \%$ of deaths were due to cardiovascular causes, $21 \%$ were due to cancer, and only $35 \%$ were directly attributable to COPD [67]. Among patients with mild airflow limitation, cancer and cardiovascular disease accounted for 50\% and $20 \%$ of the deaths, respectively.

More recent evidence supports the clustering of certain comorbidities with COPD [68], thereby suggesting potential common pathobiological pathways for these diseases. There is also increasing evidence that acute exacerbations of respiratory symptoms in patients with COPD may be caused by extrapulmonary mechanisms and exacerbations of concomitant chronic diseases, such as systemic arterial hypertension, acute heart decompensation, atrial fibrillation and pulmonary embolism [69]. Conversely, COPD exacerbations appear to impact the risk of cardiovascular events [70]. Although acute exacerbations of respiratory symptoms occur more frequently in patients with COPD, they also occur with significant frequency in smokers without COPD, suggesting that they are not specific for COPD [71, 72]. Patients with COPD have a similar prevalence of sleep apnoea as the general population. When this overlap syndrome exists, patients are treated with continuous positive airway pressure, because this has been shown to decrease mortality [73].

We recommend:

- Studies to confirm or exclude an association between specific comorbidities and COPD.

- Studies to elucidate pathobiological mechanisms linking COPD to its comorbidities.

- Studies to explore the mechanisms of exacerbations of respiratory symptoms in patients with COPD.

- Studies to determine the nature and optimal therapeutic management of patients with concomitant chronic diseases, particularly heart failure and/or ischaemic heart disease.

\section{Pathophysiology and pathology}

Tobacco smoke is the major risk factor for COPD worldwide, although other inhaled noxious particles and gases may also contribute. Inhalation of such substances causes a chronic inflammatory response and oxidative stress in the lungs of some individuals, leading to the abnormalities characteristic of COPD [74]. In addition, other pathobiological processes probably contribute, as the disease continues to progress in a substantial proportion of patients, even after inhalation of the offending agent ceases. Such processes may include genetic and epigenetically determined responses [75, 76], an imbalance of proteinases and antiproteinases [76], an abnormal interaction between environment and microbiome [76], alteration of the microbiome [77], a chronic immune response [78], inappropriate control of programmed cell death [79], accelerated lung ageing [80], pulmonary endothelial cell dysfunction [81], and abnormal ion transport due to CFTR dysfunction [82].

These mechanisms collectively cause pathological changes in four compartments of the lungs: the central airways, peripheral airways, lung parenchyma and pulmonary vasculature [83-87]. The pathological changes that give rise to the physiological abnormalities that characterise COPD include emphysema, mucus hypersecretion, ciliary dysfunction, airflow limitation, hyperinflation, abnormal gas exchange, pulmonary hypertension and various systemic effects (e.g. limb muscle weakness) [88, 89].

We recommend:

- Studies that elucidate pathways driving the chronic inflammatory response and oxidative stresses that lead to the abnormalities characteristic of COPD.

- Studies that elucidate the role of genetics, proteinases and antiproteinases, the lung microbiome, programmed cell death, mucus hypersecretion, and the pulmonary vasculature in the pathogenesis of COPD.

- Studies that compare the pathogenesis, pathology, histology, progression, prognosis, comorbidities, and treatment response of smoking-induced COPD with COPD related to other factors, including biomass fuels or occupational exposures.

- Studies that determine the influence of race, sex and socioeconomic status on the natural history and pathobiology of the disease. 


\section{Management}

Smoking cessation

Stopping smoking increases life expectancy at any age. Those who have smoked cigarettes since early adulthood but stop at 30,40 or 50 years of age gain about 10,9 and 6 years of life expectancy, respectively, compared with those who continue smoking [90]. Smoking cessation reduces the rate of decline of lung function in patients with COPD and, therefore, is an important goal of treating smokers with COPD [91]. It has been hypothesised that objective evidence of disease may motivate smokers to quit. This was supported by a study that found that communicating the results of spirometry in terms of the smoker's "lung age" (i.e. the age at which a healthy individual acquires similar results) improved the likelihood of smoking cessation [92]. However, other data are conflicting. Two studies found that smokers whose spirometry identified COPD had higher quit rates than smokers whose spirometry did not identify COPD $[93,94]$, whereas another study found that confronting smokers with abnormal spirometry results did not improve smoking cessation rates [95].

Smokers with COPD have particularly strong nicotine dependence [96]. Despite this, they appear to be just as responsive as smokers without COPD to pharmacotherapy directed at smoking cessation. This is supported by the observation that smoking quit rates were similar in trials that enrolled smokers with mild to moderate COPD, compared with trials that enrolled general populations of smokers [97-100]. It is unknown whether these findings apply to patients with severe COPD because such patients have been scarcely studied. It is likely that some comorbidities affect responsiveness to smoking cessation interventions and others do not. As examples, studies have shown that depression negatively impacts smoking cessation [101], whereas cardiovascular disease does not [102].

Pharmacological aids for smoking cessation can be allocated into two categories: controllers (e.g. nicotine patch, bupropion and varenicline), which target long-term abstinence, and relievers (e.g. nicotine gum) for rapid relief of acute cravings for tobacco or heightened withdrawal symptoms. Generally speaking, the controller medication is taken on a regular dosing schedule and the reliever is used on an as-needed basis to manage acute urges to smoke or breakthrough withdrawal symptoms. Although this strategy is intuitive, its outcomes have not been studied in controlled trials. Pharmacological therapy with two controller agents to aid smoking cessation is recommended by some guidelines due to improved efficacy compared with single agents [103-106], but the optimal combination of agents and duration of therapy remains unknown.

The combination of pharmacotherapy plus counselling improves smoking cessation compared with either pharmacotherapy or counselling alone $[107,108]$. However, the optimal intensity of counselling is unknown. In a study in which smokers with COPD received both counselling and nicotine replacement therapy, the intensity of the counselling related to improvement in the quit rate [109]. In contrast, another study found no differences between smokers who received either low- or high-intensity counselling in addition to pharmacotherapy [100].

Electronic cigarettes (i.e. e-cigarettes) are devices that, when puffed like a cigarette, produce vapours that can contain nicotine. This eliminates inhalation of most of the toxic constituents of tobacco cigarettes, although the risks of e-cigarettes are incompletely understood. E-cigarettes are growing in popularity because they have behavioural features similar to those of conventional cigarettes, yet are presumed to be a less harmful alternative that can decrease both cravings and withdrawal symptoms. They are being used as either a substitute for conventional cigarettes or as an aid to quitting smoking [110-112]. Additional research on e-cigarettes has become an urgent need, because the presumed benefits of e-cigarettes are unproven and the long-term risks are unknown, yet e-cigarettes are commercially available and becoming increasingly popular [113]. In particular, the efficacy of e-cigarettes as a smoking cessation strategy is unknown. A concern is that individuals who might otherwise avoid regular cigarette smoking due to fear of adverse health effects might be attracted to presumably safer electronic cigarettes and thereby become addicted to nicotine. In such individuals, the e-cigarettes might serve as a gateway to regular cigarette smoking. The Forum of International Respiratory Societies, which includes the ATS and ERS, has published a position statement on e-cigarettes [114].

Patients frequently fail to quit smoking and, therefore, ask whether decreased smoking is sufficient to derive some benefit. Although one study suggests that smoking reduction improves respiratory symptoms [115], it is unclear if smoking reduction slows the rate of lung function decline [116-119] like smoking cessation [91]. However, studies suggest that smoking reduction is associated with a greater probability of future cessation [119].

Electronic health records provide an opportunity to both identify smokers and offer treatment. However, one systematic review found that electronic health records were only associated with improvement in the documentation of smoking and not greater prescription of smoking cessation medications or referral to 
smoking cessation programmes. In contrast, even brief programmes that targeted patient-level interventions were more likely to increase referral to smoking cessation programmes [120].

Marijuana smoking is now legal in two states within the USA for recreational purposes and for medical purposes in several others, yet the risk of marijuana smoking on the development of COPD is uncertain. As an example, multiple studies have found that long-term marijuana smoking is associated with symptoms of COPD, but an association with fixed airflow obstruction has been inconsistent [121]. The reasons for the inconsistent findings are not understood.

We recommend:

- Studies comparing the smoking quit rate of individuals who undergo spirometry with the smoking quit rate of those who do not undergo spirometry, using different techniques to add value to the spirometry results (e.g. lung age or functional limitation). Among those undergoing spirometry, quit rates should be compared among those with and without airflow obstruction.

- Studies to clarify the optimal approach to achieve abstinence from smoking. Examples include a controller plus a reliever versus a controller or reliever alone, various combinations and durations of pharmacological agents, various intensities of counselling, and add-on therapies if initial therapy fails.

- Studies that measure the potential benefits (i.e. smoking quit rate, incidence of COPD and incidence of lung cancer) and harms (i.e. addiction rate, toxicology, carcinogenesis and cost-effectiveness) of e-cigarettes, both short- and long-term.

- Studies that compare outcomes among patients who have quit smoking, reduced the amount that they smoke, or continued smoking the same amount.

- Studies investigating the genetic basis of smoking addiction and cessation.

- Studies comparing existing smoking cessation strategies and seeking novel smoking cessation strategies and drugs.

- Studies to determine whether marijuana smoking increases the incidence of COPD and, if so, to identify which individuals are at greatest risk.

\section{Standard pharmacological therapies}

Lung function is improved and the frequency of acute COPD exacerbations is reduced by long-acting $\beta$-agonists (LABAs), inhaled corticosteroids (ICS), combined LABA/ICS, and long-acting antimuscarinic antagonists (LAMAs) $[67,122,123]$. Health-related quality of life is also improved by ICS, LABAs, LABA/ ICS, and LAMAs $[67,122,123]$. LABA/ICS and LAMAs may improve mortality in unselected patients with COPD $[66,122]$, although the evidence for this effect is limited because the studies had a low event rate due to the inclusion of patients at low risk for mortality [124].

The rate of decline of lung function might be reduced by inhaled medications according to several subgroup analyses. The first subgroup analysis [125] of a randomised trial [67] suggested that LABAs alone, ICS alone, and LABA/ICS may reduce the rate of decline of lung function among patients with varying severities of COPD. The effect was modest, as the reduced rate of decline of lung function achieved with inhaled medications was only about half that achieved with smoking cessation and sustained abstinence [125]. The second subgroup analysis [126] of a randomised trial [122] suggested that LAMAs may reduce the rate of decline of lung function among patients with moderate COPD (i.e. GOLD stage 2), even though the randomised trial found no such effect among the entire population of patients with varying severities of disease.

One reason that the effects of inhaled medications appear modest or absent in heterogeneous populations of patients with COPD is that effects may vary among COPD subtypes, such as patients who have cardiac comorbidities, have an increased risk for mortality, or have predominant emphysema or bronchial disease $[52,127]$. Although the possibility that medications have differential effects on COPD subtypes is generally accepted, early efforts at individualising treatment have had limited success. Some treatments were found to prevent exacerbations preferentially in patients with a history of chronic bronchitis and a history of exacerbations [52], and patients with a history of two or more exacerbations during the previous year responded better to preventative therapy in some studies $[128,129]$. It is uncertain whether or not current smokers respond differently to treatment than former smokers, although there is some evidence that differences may exist [130].

An as-needed inhaled short-acting $\beta$-agonist is generally the first medication initiated, often with a standing dose of an inhaled long-acting bronchodilator [9]. However, the optimal long-acting bronchodilator regimen is unknown. In a systematic review of seven randomised trials that directly compared a LAMA (i.e. tiotropium) with LABAs, meta-analyses found that the LAMA had a greater effect on reducing COPD exacerbations, exacerbation-related hospitalisations, and adverse effects, but there were no differences in mortality, all-cause hospitalisations, symptoms, or lung function [131]. 
The meta-analyses were limited by heterogeneity, suggesting that the differences between the LAMA and the LABAs may have been due to the specific LABA (i.e. salmeterol, formoterol or indacaterol), the population studied, or genetic predisposition [132]. In other words, whereas the LAMA was superior to the LABAs collectively, the possibility that one of the LABAs is superior to the LAMA in some subgroups or the entire COPD population cannot be excluded. The meta-analyses evaluated only the 12-h LABAs, because they preceded the introduction of 24-h acting LABAs; however, a subsequent direct comparison between the LAMA, tiotropium, and the 24-h LABA, indacaterol, confirmed the superiority of LAMAs in reducing exacerbations [133].

The LABA/ICS combination is sometimes given either instead of a long-acting inhaled bronchodilator alone or in addition to a LAMA. In some patients, the LABA/ICS combination improves health-related quality of life and reduces the risk of a COPD exacerbation [67]. The combination also reduces the rate of lung function decline when compared with placebo, but not when compared with a LABA alone or ICS alone [125]. The LABA/ICS combination may have a modest effect on overall mortality [67]. The primary adverse effect attributed to the LABA/ICS combination is an increased risk of pneumonia, although this effect may not be present to the same degree with all formulations of a LABA/ICS [134, 135].

The LABA/ICS combination is equivalent to a LAMA in exacerbation prevention in the only direct comparison with a LAMA [136]. Several other outcomes (i.e. health status and mortality) favour the LABA/ICS combination over the LAMA, but confidence in these results is limited by the small number of events [136]. Adding a LAMA to the LABA/ICS combination appears to reduce the rate of severe exacerbations and improve symptoms in patients with moderate or severe COPD [137].

LABA/LAMA combinations have been developed and appear to increase lung function to a greater degree than a LAMA alone [138]. The effect of the LABA/LAMA combination on the frequency of COPD exacerbations is less certain because it reduced the frequency when compared with one LAMA (i.e. glycopyrrolate) but not when compared with another LAMA (i.e. tiotropium) [138]. More studies are needed to determine the effect of the LABA/LAMA combination on other patient-centred outcomes.

Criteria for adding and withdrawing medications are uncertain. Few studies have investigated the benefits of adding medications $[137,139,140]$, and, although one trial suggested that withdrawal of ICS may not increase the risk of moderate or severe COPD exacerbations [141], there is an overall paucity of evidence about when COPD medications can be safely withdrawn. To monitor pharmacotherapy, tools are needed to facilitate objective assessment of the effects of medications [142-144].

Adherence to inhaled medications has a significant impact on patient-centred outcomes, including mortality and hospital admissions [145]. Administrative database analysis suggests that less frequent dosing is one way to improve adherence [146]. Additional strategies that may improve adherence include the method of administration (e.g. nebuliser or inhaler) and various behavioural approaches (e.g. assessing inhaler technique); however, the effectiveness of such interventions has not been confirmed due to insufficient study [147-149].

A high proportion of patients with COPD have poor inhaler technique, which appears to negatively affect outcomes [148]. Choosing the right device for a given patient, educating on inhaler technique, and regularly checking inhaler use are important components of COPD management [150].

We recommend:

- Therapeutic trials that analyse outcomes among different COPD subtypes, particularly those subtypes that are at greatest risk for an undesirable outcome.

- Therapeutic trials that compare outcomes among current smokers with former smokers.

- Therapeutic trials that evaluate outcomes using different thresholds for initiating, adding and withdrawing medications.

- Therapeutic trials that compare outcomes among patients treated with different medications (as opposed to placebo-controlled studies). Examples include: 1) comparisons of LAMA therapy with each type of LABA therapy (i.e. salmeterol, formoterol, indacaterol, olodaterol and vilanterol); and 2) comparisons of combination LAMA/LABA therapy with LABA/ICS, LAMA, and LABA therapy.

- Trials comparing strategies of pharmacological treatment (e.g. treatment initiation with one single agent and then further step-up if symptoms are not controlled versus immediate double or triple therapy).

- Studies of therapies aimed at improving cough, sputum production and dyspnoea, all of which are of important to patients.

- Studies assessing how pharmacological treatment complements rehabilitation programmes.

- Real-life observational studies (i.e. effectiveness studies) that assess how the results of randomised trials (i.e. efficacy trials) may be applied to broader patient populations in usual care settings.

- Studies that determine the risk for pneumonia conferred by each formulation of the LABA/ICS combination, as well as the aetiology and natural history of pneumonia in patients treated with ICS. 
- Studies that evaluate the effects of treating common comorbidities on COPD-specific outcomes, as well as the effects of treating COPD on outcomes specific to common comorbidities.

- Studies that identify and validate instruments that objectively determine a patient's response to therapy.

- Studies that compare outcomes among patients managed with various strategies to improve adherence. Examples include inhaler choice and education.

- Studies that compare outcomes among patients who use an inhaler with those who use a nebuliser.

- Studies of patients who are diagnosed with COPD at an early age to determine if early intervention reduces disease progression.

\section{Novel pharmacological therapies}

Anti-inflammatory therapies

Chronic inflammation is likely to contribute to both the pathophysiology of COPD and its associated morbidities [151]. However, inflammation is complex and, in COPD, seems to represent amplification of the normal response of the respiratory tract to inhaled irritants, mainly cigarette smoke and biomass [152, 153].

Many inflammatory cells and mediators are involved in COPD inflammation, so there are many potential targets. However, treatments that are too specific or downstream may have little effect or target only a small proportion of patients (i.e. responder phenotypes), as demonstrated by single mediator antagonists that have proven ineffective, including tumour necrosis factor- $\alpha$, interleukin (IL)- $1 \beta$, and IL- 5 blocking antibodies [154, 155].

Broad-spectrum anti-inflammatory treatments seem more likely to be effective, but frequent side-effects occur when such agents are given orally. This supports inhaled strategies, although this approach will likely have little effect on inaccessible areas of the lung or systemic features. Both ICS/LABA and ICS alone are anti-inflammatory agents. The phosphodiesterase 4 inhibitor, roflumilast, is a therapy with anti-inflammatory properties that has some efficacy, but the dose is limited by side-effects such as diarrhoea, nausea and headaches [156]. There is in vitro evidence of LAMAs having anti-inflammatory properties, but clinical studies have failed to confirm this effect [157]. Inhibitors of p38 mitogen-activated protein kinase may be useful, but previous studies in rheumatoid arthritis demonstrated frequent side-effects and loss of efficacy with time (i.e. tolerance). Oral p38 mitogen-activated protein kinase inhibitors have small effects [158] or no effects [159], and inhaled drugs are in development. Other kinases targeted for COPD include Janus-activated kinase, phosphoinositide-3-kinase, and spleen tyrosine kinase, but no clinical studies have been reported. Reversing corticosteroid resistance is currently being explored in large trials of low-dose theophylline and phase II studies with inhaled phosphoinositide-3-kinase $\delta$ inhibitors [160].

Biomarkers may predict responsiveness to anti-inflammatory therapies. As examples, a history of COPD exacerbations, circulating eosinophilia, and/or sputum eosinophilia predicts responsiveness to corticosteroids $[161,162]$. They might also predict responsiveness to a monoclonal antibody that appears to be effective in eosinophilic severe asthma $[163,164]$.

Antioxidant therapies may be useful in the prevention of exacerbations. However, their effect on stable inflammation and disease progression has yet to be proven. Although current drugs appear ineffective, there is recent interest in activators of Nrf2, which regulates antioxidant genes, particularly because Nrf2 function is defective in COPD.

Long-term antibiotic therapy

Long-term macrolides have been used to prevent recurrent exacerbations. In addition to their antibacterial activity, other potentially beneficial effects of macrolides include an anti-inflammatory effect, enhanced phagocytic activity of macrophages [165], increased antiviral effects [165, 166], and gastric prokinetic effects.

Randomised, placebo-controlled clinical trials have confirmed a reduction in the frequency of exacerbations of COPD with long-term use of macrolides. However, the trials used different drugs with different administration regimens and enrolled populations with different inclusion and exclusion criteria [167, 168]. Thus, although the effect might be greater in older patients and milder COPD and less in current smokers [130], the patient population for which macrolides are indicated, the best dosage, and the optimal duration of treatment still need to be determined. The mode of action (i.e. anti-inflammatory or antimicrobial), differential effects among the various macrolides, and effects of therapy on other patient-centred outcomes also need to be elucidated. The use of macrolides has been associated with increased risk of cardiovascular events in some database studies [169-171]; however, the 1-year incidence of cardiovascular death was minimal (one out of 558 patients who received a macrolide) in a trial that excluded patients with COPD who had a resting heart rate $>100$ beats per min, had a corrected QT (QTc) interval $>450 \mathrm{~ms}$, or were using medications known to prolong the QTc interval or be associated with torsades de pointes, suggesting that the risk is low if patients are properly selected for macrolide therapy [167]. In addition, chronic use of macrolides 
may be associated with the acquisition of antibiotic resistance. As a result, macrolides are initiated on a case-by-case basis after carefully weighing the benefits versus risks for each patient.

The fluoroquinolone moxifloxacin has been used as a 5-day pulse every 8 weeks to reduce the frequency of exacerbations in patients with moderate to severe COPD. In a randomised, placebo-controlled trial, moxifloxacin reduced exacerbations by $25 \%$ overall and up to $45 \%$ in the subgroup of patients with purulent or mucopurulent sputum at baseline [172]. Results suggest that moxifloxacin is particularly effective in reducing bacterial exacerbations in patients who are likely to be colonised by bacteria other than Pseudomonas aeruginosa. However, the types of patients most likely to benefit from long-term fluoroquinolone therapy, the best dosage, the optimal duration of treatment, the mode of action, the effects on other patient-centred outcomes, and whether there are differences among the various fluoroquinolones remain unknown.

Many other antibiotics exist that have never been studied, including other macrolides and fluoroquinolones, as well as other classes of antibiotics. It is unknown whether such alternatives are less effective, similarly effective, or more effective than those that have been systematically studied. In addition, the long-term safety of such agents needs to be determined, including side-effects and the emergence of bacterial resistance.

\section{Statin therapy}

Statins inhibit conversion of HMG-CoA (3-hydroxy-3-methylglutaryl-coenzyme A) to mevalonate, which accounts for the immune modulating effects in both systemic and pulmonary circulation. In animal models, statins are anti-inflammatory and have demonstrated beneficial effects on lung parenchyma, airways and vasculature [173].

Predominantly observational evidence about the effects of statins in COPD suggested that statins are associated with a lower rate of FEV1 decline [174], decreased airflow limitation [175], fewer re-hospitalisations due to COPD [176], reduced cardiovascular morbidity and mortality [177, 178], decreased all-cause mortality $[177,178]$, and improved exercise tolerance and dyspnoea among patients with coexisting hypertension [179]. However, the National Institutes of Health and Canadian Institute of Health Research subsequently reported the results of a randomised trial that compared regular use of simvastatin with placebo, the STATCOPE study. The study found that simvastatin did not improve the frequency of acute exacerbations of COPD or other outcomes (lung function, health status or hospitalisations) in patients who do not have other indications for statin therapy. Subgroup analyses similarly found no differences [180].

We recommend:

- Continued scientific exploration of new anti-inflammatory pathways and agents that mitigate the inflammatory response to inhalational injury.

- Controlled clinical trials that compare the effects of various long-term antibiotic regimens with one another.

- Controlled clinical trials of long-term antibiotic therapy that compare outcomes among subtypes of patients with COPD, various dosages, and varying durations of therapy. Outcomes should include the emergence of bacterial resistance, in addition to the usual benefits and side-effects.

- Controlled clinical trials that compare the effects of novel anti-inflammatory agents with placebo on outcomes. If a beneficial effect is confirmed, then additional trials are warranted to compare outcomes among subtypes of patients with COPD, dosages, and durations of therapy.

\section{Managing comorbidities}

Management of the rising prevalence of multiple chronic comorbidities (i.e. patients with two or more chronic morbidities) is a major challenge facing healthcare systems worldwide [181]. In many patients, COPD should be considered to be just one component of multiple chronic comorbidities. Generally speaking, patients with COPD and multiple chronic comorbidities are treated according to existing standards for each individual disease. In other words, comorbidities in patients with COPD are treated the same as in patients without COPD, and COPD is treated the same regardless of the comorbidity. Indeed, observational studies suggest that mortality of patients with COPD can be reduced by non-respiratory treatments, including $\beta$-blockers, angiotensin-converting enzyme inhibitors [182], and statins [183].

We recommend:

- Studies that evaluate the effects of treating COPD on the outcomes of comorbid diseases, as well as studies that evaluate the effect of treating comorbid diseases on COPD-related outcomes.

\section{Nonpharmacological therapies}

\section{Pulmonary rehabilitation}

Pulmonary rehabilitation is typically provided in a hospital-based, outpatient setting. Its benefits in this setting are well established, including reduced dyspnoea, increased exercise capacity, improved quality of 
life, and reduced use of healthcare resources [184]. Effects on physical activity are less studied and less consistent, but are generally considered clinically significant. More recent research has focused on the effectiveness of pulmonary rehabilitation in alternative settings.

Home-based pulmonary rehabilitation might improve patient-centred outcomes, including health-related quality of life and exercise capacity, to an extent comparable to hospital-based programmes [185]. A randomised trial supports the effectiveness of home-based pulmonary rehabilitation. The trial compared cycle ergometer exercise training in the home with the same training in a pulmonary rehabilitation centre [186]. All patients had participated in a 4-week educational programme before randomisation to an exercise training site. Dyspnoea and exercise tolerance improved to an equivalent degree in both groups, and there were no significant safety issues in either group. However, critics have argued that the magnitude of benefit in the hospital-based pulmonary rehabilitation group was smaller than usual, potentially biasing the results toward no difference. This highlights the need for confirmatory studies before concluding that home-based pulmonary rehabilitation programmes provide outcomes similar to hospital-based programmes.

Community-based pulmonary rehabilitation has been compared with no pulmonary rehabilitation in a 2-year randomised trial, which found that community-based pulmonary rehabilitation improved dyspnoea, exercise endurance, strength and nutritional indices $[187,188]$. The total cost of the intervention was higher than usual care at 4 months, but this was offset at 24 months due to reduced hospital admission costs.

Pulmonary rehabilitation programmes are also effective in patients after (severe) exacerbations. A systematic review identified clear benefits in terms of symptoms, health-related quality of life and exercise tolerance, as well as possible benefits in hospital readmission rates and survival [189].

Pulmonary rehabilitation and pharmacotherapy appear to be complementary approaches to COPD care with synergistic effects [190]. Additional details about the evidence for pulmonary rehabilitation in patients with COPD are provided in an ATS/ERS statement on pulmonary rehabilitation [184].

We recommend:

- Studies that compare the effects of home-based pulmonary rehabilitation with hospital-based pulmonary rehabilitation.

- Studies that compare hospital-based, home-based, and community-based pulmonary rehabilitation in different subtypes of patients with COPD, to determine which settings are most appropriate for the various types of patients.

- Long-term studies that compare the effects of hospital-based, home-based, and community-based pulmonary rehabilitation on the maintenance of benefits. Of particular importance is evaluation of the effects of such programmes on physical activity.

- Studies that compare the effects of various modalities, supervision protocols, and programme durations on outcomes.

- Controlled trials of early intensive rehabilitation in patients recovering from exacerbations to evaluate its potential effect on readmission rates and other outcomes.

- Studies that evaluate strategies to maintain the benefits of pulmonary rehabilitation.

Long-term oxygen therapy

Long-term oxygen therapy (LTOT) reverses hypoxaemia. A trial that compared LTOT with no oxygen therapy in patients with COPD and severe hypoxaemia (arterial oxygen tension $\left(\mathrm{PaO}_{2}\right) \leqslant 55 \mathrm{mmHg}$ ) found that LTOT improved survival [191], whereas another trial that compared oxygen administered $19 \mathrm{~h}$ per day with oxygen administered $12 \mathrm{~h}$ per day found that the longer duration improved survival [192]. In contrast, a trial that compared LTOT with no oxygen therapy in patients with COPD and moderate hypoxaemia $\left(\mathrm{PaO}_{2} \leqslant 69 \mathrm{mmHg}\right)$ found no effect on survival, regardless of the duration used per day [193]. The evidence has important limitations: the trials included relatively few patients and events (only 370 patients and 164 deaths, collectively), there was a paucity of women enrolled in the trials, and two of the three trials were conducted more than 30 years ago. A trial that compared nocturnal oxygen therapy (as opposed to continuous oxygen therapy) with no nocturnal oxygen therapy in patients with COPD and hypoxaemia found no effect on survival [194].

These data suggest that LTOT has a mortality benefit that may be related to the severity of hypoxaemia (i.e. the mortality benefit was seen only among patients with severe hypoxaemia). Thus, LTOT is routinely prescribed for patients with severe hypoxaemia. The National Institutes of Health has funded a multicentre trial comparing supplemental oxygen with no supplemental oxygen among patients with mild to moderate hypoxaemia, the Long-term Oxygen Treatment Trial (LOTT). Among patients in the supplemental oxygen group, those with hypoxaemia at rest will be instructed to use the supplemental oxygen continuously, whereas those with hypoxaemia during exertion will be instructed to use the supplemental oxygen with exertion and during sleep only. 
LTOT incurs cost but has few adverse clinical effects [195]. The major hazard is fires or explosions [196, 197]. These consequences of LTOT are the reasons that prescribing LTOT for current smokers is controversial.

We recommend:

- Studies that measure the effects of LTOT on outcomes in various COPD subtypes. Examples of subtypes that warrant evaluation include patients with mild and moderate hypoxaemia, desaturation with exertion, desaturation during sleep, comorbid heart disease, frequent exacerbations, decreased exercise capacity or pulmonary hypertension.

- Studies that evaluate the effect of LTOT on physical activity and the relationship of this effect on other outcomes, such as quality of life, frequency of exacerbations and mortality.

- Studies that compare the effects of various modalities of LTOT (e.g. continuous, exercise, sleep, combined, with or without flow titration) on outcomes in different patient subtypes.

Noninvasive mechanical ventilation

Noninvasive mechanical ventilation (NIV) improves respiratory acidosis and decreases respiratory rate, severity of breathlessness, intubation rate, length of hospital stay, and mortality in patients with COPD who are experiencing acute on chronic respiratory failure [198-202]. Despite the success of NIV for acute respiratory failure, the effects of long-term NIV in patients with COPD who have chronic respiratory failure remain controversial [203, 204]. Some studies have shown benefits in health status, dyspnoea, or blood gases, but there has been little or no impact on other outcomes such as re-hospitalisation rates or mortality [205-207]. An exception is a recent study that found that NIV may improve survival in patients with COPD with chronic respiratory failure [208]. Uncertainty about the effects of NIV in patients with COPD with chronic respiratory failure has led to the use of NIV on an individual basis; more studies are necessary to confirm the effects of NIV and identify patients who are likely to benefit from NIV.

We recommend:

- Studies that assess the effects of long-term NIV in patients with COPD who have chronic respiratory failure.

- Studies that identify characteristics of patients who are most likely to benefit from long-term NIV.

Lung volume reduction therapies

Lung volume reduction approaches may be a useful complement to standard medical therapy for a select number of patients with advanced COPD. Patients who harbour giant bullae (i.e. isolated gas-filled cavities occupying one-third of the ipsilateral hemithorax) surrounded by relatively normal parenchyma can obtain significant improvements in lung mechanics, symptoms, functional performance and health status from bullectomy [209].

The value of lung volume reduction surgery for other COPD phenotypes is controversial. The National Emphysema Treatment Trial suggested that patients with severe COPD (defined as an FEV1 <45\% predicted) with a predominance of emphysema in the upper lobes and with reduced exercise capacity (defined as maximal exercise capacity $<25 \mathrm{~W}$ for women and $<40 \mathrm{~W}$ for men on a standard incremental cycle ergometer test) may experience significant improvements in symptoms, health status, lung mechanics, exacerbation rates, and even survival with lung volume reduction surgery [210]. However, the therapy is costly, with a cost-effectiveness ratio of $\$ 98000$ per 1 quality-adjusted life-year saved over 3 years [211]. Moreover, $90 \%$ of patients who undergo lung volume reduction surgery experience significant air leaks after thoracotomy that result in a prolonged hospital stay and morbidity. For these reasons, several bronchoscopic methods are under investigation to selectively reduce lung volumes. However, none have received regulatory approval for use in COPD owing to limited efficacy and concerns about increased risk of pneumonia and exacerbations [212].

We recommend:

- Studies to evaluate whether or not minimally invasive surgical techniques can reduce complication rates and improve perioperative outcomes and costs compared with conventional surgical techniques.

- Studies to evaluate whether or not the benefits of lung volume reduction surgery observed in trials during the late 1990s and early 2000s are still applicable in the current era in light of advances in medical management for COPD.

- Studies to evaluate bronchoscopic lung volume reduction techniques that are intended to increase benefits and reduce complications, especially those related to pneumonia.

Lung transplantation

COPD is the most common indication for lung transplantation, accounting for $35 \%$ of lung transplants [213]. Among patients with severe COPD, lung transplantation improves survival [214, 215] and health-related quality of life [216]. 
Each patient requires an individualised assessment of his or her suitability. However, prognostic indices used to demonstrate the need for transplantation include 1) an FEV1 $<20 \%$ pred plus either a DLCO $<20 \%$ or homogenous emphysema on imaging (these criteria are associated with increased mortality after lung volume reduction surgery as compared with medical treatment), 2) evidence of secondary pulmonary hypertension (or cor pulmonale) despite adequate oxygenation, and 3) a history of hospitalisation with acute hypercapnic respiratory failure with arterial carbon dioxide tension $>50 \mathrm{mmHg}$ [180]. In addition, candidates need to be free of single major contraindications or multiple minor contraindications. A BODE (body mass index, airflow obstruction, dyspnoea and exercise capacity index) score of 7 or more was proposed as another indicator for lung transplantation [215, 217]; however, its applicability for this purpose is unclear.

Bilateral lung transplantation may be a better option than single lung transplantation, as it is associated with better long-term outcomes, at least among patients younger than 60 years [218]. However, the advantages of bilateral lung transplantation over single lung transplantation are less clear if the risk of death while still on the waiting list is considered [219, 220].

We recommend:

- Studies to evaluate whether using a poor survival predicted by the BODE index as an indication for listing patients with COPD for lung transplantation is associated with better outcomes than using alternative indications for lung transplantation.

- Studies that compare outcomes after lung transplantation with those achieved by medical management alone.

- Studies to determine whether the anticipated improvements in symptoms and quality of life after lung transplantation are sufficient to justify the donor resource or whether improvement in mortality is also necessary.

- Studies that compare outcomes after bilateral and unilateral lung transplantation and assess which subtypes of patients benefit more from one rather than the other.

\section{Nutrition}

Low body weight in COPD may be a marker of systemic disease. If weight loss is observed, it may be a consequence of reduced oral intake, increased energy expenditure and metabolic alterations due to low-grade systemic inflammation, and increased protein consumption [221]. Low body weight is associated with increased mortality and reduced health status, quality of life and exercise capacity. However, the magnitude of weight loss does not correlate with the severity of airflow limitation [39, 222-224].

Several measurements have been considered as potential prognostic indicators. A BMI $<21 \mathrm{~kg} \cdot \mathrm{m}^{-2}$ is associated with significantly worse clinical outcomes [39]. Muscle or fat-free mass measurements may be even better predictors of clinical outcomes [223, 224]. Acute involuntary weight loss is also important.

Nutritional intervention in COPD generally begins with dietary supplements once alternative causes of weight loss are excluded. Systematic reviews provide conflicting information. One systematic review found that dietary supplementation improved body weight and grip strength [225], whereas another systematic review found nonsignificant trends toward a beneficial effect of nutritional supplementation on anthropometric measures, lung function and exercise capacity [226]. Alternative metabolic treatments, including androgens and human growth hormone, have also been tried, but their long-term effects remain unknown [227]. Micronutrients may also play a role in COPD. Low vitamin D levels have been associated with both reduced lung function and emphysema [228]. Few studies of vitamin D replacement have been conducted, and they have not shown benefits [229].

Obesity and its multiple chronic comorbidities are common and also need to be addressed in patients with COPD [228].

We recommend:

- Studies to determine why some patients with COPD develop weight loss and malnutrition and other patients do not.

- Studies that evaluate the outcomes of nutritional therapies (e.g. dietary supplements, androgens and human growth hormone) in patients with COPD with weight loss.

\section{Integrative management}

Integrated care programmes or disease management programmes are systematic approaches to reduce the fragmentation of patient care. Integrated care programmes in COPD include patient self-education, coordinated care, self-management [230], home care [231], and interventions that address the rehabilitative and psychological aspects of the disease [232], with or without support via information technologies [233]. 
Early initiation of treatment for acute exacerbations has been the primary goal of most COPD integrative disease programmes. Evidence regarding the effectiveness of integrative care programmes is conflicting. A randomised trial found that an intensive self-management comprehensive educational programme in patients previously hospitalised for exacerbations decreased hospital readmissions during the following year [230]. Another randomised trial similarly reported that a single 1.5-h education session, an action plan for self-treatment of exacerbations, and monthly nurse case management phone follow-ups reduced COPD-related hospitalisations or emergency room visits by 34\% [234]. However, a similar trial that compared comprehensive case management programme with standardised COPD care was prematurely discontinued due to excessive mortality in the comprehensive case management group [235]. Several other studies in COPD have failed to show significant improvement in outcomes with predominantly nurse-led home management programmes [236]. Reasons for the disparate results are unclear, but it appears that close contact with patients who have a high disease burden is crucial for maximising success. Variations in the programme components, the duration of the intervention, and the outcomes measured have led to uncertainty about how to develop a successful integrative care model for COPD [237].

Evidence regarding telemedicine-based disease management in COPD is conflicting and limited by the small patient numbers, use of variable intensities of telemonitoring, and lack of prespecified treatment plans [238]. In a randomised trial of patients with chronic respiratory failure (42\% had COPD), those randomised to receive tele-assistance had fewer hospitalisations, less urgent calls, and decreased acute exacerbations. In the COPD subgroup, there were decreased home visits and hospitalisations among those who were managed via the tele/home care model, with a substantial cost saving at 6 months [239]. In contrast, another study found that home-based COPD telemonitoring programmes conferred no benefit in decreasing hospital or homecare costs [240, 241].

Self-management is receiving increasing attention in chronic diseases. Self-management studies should be designed with realistic outcome goals and ensure that the outcome goals, characteristics of optimal patient candidates, and essential elements of educational tools and processes are well defined. Studies should also demonstrate that self-management programmes can be safely and broadly applied to patients with COPD.

We recommend:

- Studies that compare different combinations of components of integrative care programmes, to identify which combinations optimise outcomes.

- Studies that measure the outcomes of integrative care in subtypes of patients with COPD.

- Studies that compare the outcomes of different durations of integrative care.

- Studies that assess the cost-effectiveness of integrative care in COPD.

- Studies that evaluate the effects of the educational/self-management components of pulmonary rehabilitation on patient-centred outcomes.

\section{End-of-life care}

Studies have reported that most patients with COPD desire a discussion regarding end-of-life care with their physician, but these discussions occur only 30\% of the time [242]. When end-of-life discussions occur in patients with COPD, most occur during an acute exacerbation rather than a more stable state of their disease, and the skill of the providers leading the discussion is commonly inadequate [243-245]. Similarly, palliative care is often not addressed or inadequately addressed in patients with COPD, permitting symptoms whose mitigation or elimination would provide comfort to patients with COPD, such as dyspnoea, cough, pain and fatigue, and less commonly poor sleep quality, depression and anxiety $[246,247]$. Up to $30 \%$ of patients with advanced COPD with multiple symptoms are not on optimised therapy [248].

Barriers that limit advanced care (i.e. both end-of-life and palliative) planning between patients with COPD and providers have been identified [249]. Most notably, providers frequently believe that advanced care planning is difficult to do in COPD. Many factors contribute to this perception: inadequate information about the likely course of COPD, lack of agreement as to whether the primary care provider or the respiratory specialist is responsible for initiating advanced care planning, uncertainty about what defines end-of-life care in COPD (i.e. use of oxygen, being housebound or frequent severe exacerbations), and uncertainty about whether end-of-life and palliative care are compatible with the goals of chronic disease management [249]. Similar issues prevent patients with COPD and physicians from advanced care planning in the USA and the Netherlands, despite the cultural and healthcare delivery system differences between the two countries [250].

We recommend:

- Studies that demonstrate the impact of palliative care and end-of-life discussions on outcomes in patients with stable COPD. 
- Studies of educational approaches and tools to help clinicians better discuss palliative care and end-of-life care with patients with COPD.

- Studies to confirm the importance of optimised therapy in minimising symptoms at the end of life.

- Studies that identify symptoms that occur despite optimised COPD care and require palliation. Such studies should be followed by trials that compare the effects of various treatment options on those symptoms.

\section{Preoperative evaluation}

COPD is a risk factor for both intraoperative and postoperative pulmonary complications after lung resection. A cardiac evaluation is frequently performed as part of the preoperative assessment of patients with COPD because many of the risk factors for COPD are also risk factors for cardiac disease. Generally speaking, patients with acceptable exercise tolerance receive only an ECG, whereas patients with limited exercise capacity may undergo noninvasive cardiac testing to identify those with unsuspected cardiac disease who require additional evaluation [251-253]. There is no evidence that prophylactic cardiac revascularisation reduces postoperative risk in patients with COPD [254].

The FEV1 and DLCO are routinely measured preoperatively to predict postoperative pulmonary function, morbidity and mortality. Most patients whose FEV 1 and DLCO are both $>80 \%$ pred do not undergo further preoperative testing $[255,256]$, whereas those whose FEV1 or DLCO are $<80 \%$ pred undergo further assessment of their predicted postoperative pulmonary function $[257,258]$. Quantitative ventilation or perfusion lung scanning predicts postoperative pulmonary function by objectively measuring the contribution of individual lung lobes [256]. The combination of ventilation and perfusion scanning offers no additive predictive benefit compared with either technique alone [259]. The maximum symptom limited exercise testing, 6-min walk test, incremental shuttle walk test, and stair climb are alternative methods to predict postoperative pulmonary complications.

Perioperative risk increases when the predicted postoperative DLCO is $<40 \%$ [260-262] or the predicted postoperative $\mathrm{FEV}_{1}$ is $<40 \%$ pred. The latter has been associated with mortality rates ranging from $16 \%$ to $50 \%$ [263-266]. Mortality rates as high $60 \%$ have been reported when the predicted postoperative FEV 1 is $<30 \%[267,268]$. However, because many patients qualified as at high risk after calculation of predicted postoperative lung function can undergo surgery safely, decisions are made on an individual basis [269].

Although the predicted postoperative $\mathrm{FEV}_{1}$ is the best parameter in predicting postoperative complications after resection, its limitations are that it is unreliable in predicting outcomes among patients whose preoperative $\mathrm{FEV}_{1}$ is $>70 \%$, and it is most accurate in predicting lung function 3 to 6 months after a lobectomy [270]. The post-lobectomy FEV1 may be more than $30 \%$ lower than the predicted value during the first days to weeks postoperatively.

We recommend:

- Studies in patients with COPD undergoing lung resection that compare outcomes among patients who had their postoperative lung function predicted quantitatively with those among patients who had their postoperative lung function predicted qualitatively. Such studies should perform the comparison using different combinations of preoperative FEV1 and DLCO in the quantitative arm(s).

- Studies in patients with COPD undergoing lung resection comparing outcomes among patients whose risk for perioperative complications was determined via predicted postoperative lung function measurements with those among patients whose risk was determined via exercise testing.

\section{Air travel risk assessment}

Commercial aircraft are pressurised to cabin altitudes of 8000 feet $(2438 \mathrm{~m})$, at which the partial pressure of inspired oxygen falls to the equivalent of $15.1 \%$ oxygen at sea level. In healthy individuals, oxygen saturation measured by pulse oximetry decreases to $89-94 \%$ during rest and to even lower levels during exercise or sleep. Patients with pulmonary disease have lower oxygen saturation at baseline; thus, the decrease that occurs at a high altitude may result in hypoxaemia that can be severe. As an example, a stable patient with COPD with an oxygen saturation of $93 \%$ during rest at sea level may experience oxygen desaturation to $82 \%$ at rest during a commercial air flight and may experience symptoms of hypoxaemia. Even lower levels of oxygen saturation may be encountered during periods of in-flight mild exercise or sleep [271].

Patients with COPD who use oxygen at sea level are always prescribed supplemental oxygen during commercial air travel $[272,273]$. For patients who do not use oxygen at sea level, further assessment is generally performed if the resting preflight oxygen saturation is $<92 \%$. This may include a $50-\mathrm{m}$ walk test or a high-altitude simulation using either a hypobaric chamber or a high-altitude stimulation test [272, 274-277]. High-altitude stimulation testing involves breathing gases with lower than normal oxygen concentration. If oxygen desaturation occurs with any of these tests, then supplemental oxygen is generally 
prescribed. Although these tests identify patients in whom supplemental oxygen is necessary to mitigate in-flight hypoxaemia, they cannot exclude the possibility of in-flight hypoxaemia among patients who have a resting preflight oxygen saturation $>92 \%$ [277] or who do not desaturate during testing [273].

The in-flight flow rate is typically $2 \mathrm{~L} \cdot \mathrm{min}^{-1}$ higher than the rate used at sea level. Commercial airlines routinely accept in-flight oxygen prescriptions of $2 \mathrm{~L} \cdot \mathrm{min}^{-1}$ or $4 \mathrm{~L} \cdot \mathrm{min}^{-1}$. Higher levels of oxygen prescription are not available, and patients who need higher levels of inspired oxygen are discouraged from air travel.

We recommend:

- Studies to determine the impact of flight duration and comorbidities on in-flight respiratory complications in patients with COPD.

- Studies that directly compare different preflight strategies for determining which patients with COPD are at risk for in-flight respiratory complications.

- Studies that directly compare different preflight strategies for determining which patients with COPD will benefit from in-flight supplemental oxygen.

- Studies that determine the minimum level of oxygenation necessary to protect patients with COPD from in-flight respiratory complications.

- Studies that determine whether in-flight respiratory complications are generally due to altitude-related hypoxia alone or also other factors (e.g. recycled cold dry air or immobility).

\section{Conclusions}

COPD is a leading cause of morbidity, mortality and resource use worldwide. Great strides have been made in the identification, pathogenesis, assessment and treatment of COPD. Despite this, many important questions remain unanswered. This ATS/ERS research statement highlights the types of research that leading clinicians and researchers believe will have the greatest impact on outcomes, including studies that determine the impact of COPD-related clinical practice guidelines on outcomes in patients with COPD.

\section{Acknowledgements}

This guideline was prepared by an ad hoc ATS/ERS Task Force for COPD Research. Co-chairs: Bartolome R. Celli, Marc Decramer, Jadwiga A. Wedzicha and Kevin C. Wilson; group leaders: Alvar Agustí, Gerard J. Criner, William MacNee, Barry J. Make, Stephen I. Rennard, Robert A. Stockley and Claus Vogelmeier; committee members: Antonio Anzueto, David H. Au, Peter J. Barnes, Pierre-Regis Burgel, Peter M. Calverley, Ciro Casanova, Enrico M. Clini, Christopher B. Cooper, Harvey O. Coxson, Daniel J. Dusser, Leonardo M. Fabbri, Bonnie Fahy, Gary T. Ferguson, Andrew Fisher, Monica J. Fletcher, Maurice Hayot, John R. Hurst, Paul W. Jones, Donald A. Mahler, François Maltais, David M. Mannino, Fernando J. Martinez, Marc Miravitlles, Paula M. Meek, Alberto Papi, Klaus F. Rabe, Nicolas Roche, Frank C. Sciurba, Sanjay Sethi, Nikos Siafakas, Don D. Sin, Joan B. Soriano, James K. Stoller, Donald P. Tashkin, Thierry Troosters, Geert M. Verleden, Johny Verschakelen, Jorgen Vestbo, John W. Walsh, George R. Washko, Robert A. Wise, Emiel F.M. Wouters and Richard L. ZuWallack.

\section{References}

1 Lozano R, Naghavi M, Foreman K, et al. Global and regional mortality from 235 causes of death for 20 age groups in 1990 and 2010: a systematic analysis for the Global Burden of Disease Study 2010. Lancet 2012; 380: 2095-2128.

2 Miniño AM, Xu J, Kochanek KD. Deaths: preliminary data for 2008. Natl Vital Stat Rep 2010; 59: 1-52.

3 López-Campos JL, Ruiz-Ramos M, Soriano JB. Mortality trends in chronic obstructive pulmonary disease in Europe, 1994-2010: a joinpoint regression analysis. Lancet Respir Med 2014; 2: 54-62.

$4 \quad$ Murray CJ, Lopez AD. Measuring the global burden of disease. N Engl J Med 2013; 369: 448-457.

5 Thun MJ, Carter BD, Feskanich D, et al. 50-year trends in smoking-related mortality in the United States. N Engl J Med 2013; 368: 351-364.

6 Guarascio AJ, Ray SM, Finch CK, et al. The clinical and economic burden of chronic obstructive pulmonary disease in the USA. Clinicoecon Outcomes Res 2013; 5: 235-245.

7 Celli BR, MacNee W, Agusti A, et al. ATS/ERS Task Force. Standards for the diagnosis and treatment of patients with COPD: a summary of the ATS/ERS position paper. Eur Respir J 2004; 23: 932-946.

8 Vestbo J, Hurd SS, Agustí AG, et al. Global strategy for the diagnosis, management, and prevention of chronic obstructive pulmonary disease: GOLD executive summary. Am J Respir Crit Care Med 2013; 187: 347-365.

9 O'Reilly J, Jones MM, Parnham J, et al. Guideline Development Group. Management of stable chronic obstructive pulmonary disease in primary and secondary care: summary of updated NICE guidance. BMJ 2010; 340: $\mathrm{c} 3134$.

10 Rostron BL, Chang CM, Pechacek TF. Estimation of cigarette smoking-attributable morbidity in the United States. JAMA Intern Med 2014; 174: 1922-1928.

11 Barnett K, Mercer SW, Norbury M, et al. Epidemiology of multimorbidity and implications for health care, research, and medical education: a cross-sectional study. Lancet 2012; 380: 37-43.

12 Jones P, Miravitlles M, van der Molen T, et al. Beyond FEV1 in COPD: a review of patient-reported outcomes and their measurement. Int J Chron Obstruct Pulmon Dis 2012; 7: 697-709.

13 Roche N, Gaillat J, Garre M, et al. Acute respiratory illness as a trigger for detecting chronic bronchitis in adults at risk of COPD: a primary care survey. Prim Care Respir J 2010; 19: 371-377.

14 Cote CG, Casanova C, Marín JM, et al. Validation and comparison of reference equations for the 6-min walk distance test. Eur Respir J 2008; 31: 571-578. 
Oga T, Nishimura K, Tsukino M, et al. Analysis of the factors related to mortality in chronic obstructive pulmonary disease: role of exercise capacity and health status. Am J Respir Crit Care Med 2003; 167: 544-549. Coxson HO, Lam S. Quantitative assessment of the airway wall using computed tomography and optical coherence tomography. Proc Am Thorac Soc 2009; 6: 439-443.

Copley SJ, Wells AU, Müller NL, et al. Thin-section CT in obstructive pulmonary disease: discriminatory value. Radiology 2002; 223: 812-819.

Coxson HO, Mayo J, Lam S, et al. New and current clinical imaging techniques to study chronic obstructive pulmonary disease. Am J Respir Crit Care Med 2009; 180: 588-597.

Barr RG, Berkowitz EA, Bigazzi F, et al. COPDGene CT Workshop Group. A combined pulmonary-radiology workshop for visual evaluation of COPD: study design, chest CT findings and concordance with quantitative evaluation. COPD 2012; 9: 151-159.

Galbán CJ, Han MK, Boes JL, et al. Computed tomography-based biomarker provides unique signature for diagnosis of COPD phenotypes and disease progression. Nat Med 2012; 18: 1711-1715.

Christe A, Charimo-Torrente J, Roychoudhury K, et al. Accuracy of low-dose computed tomography (CT) for detecting and characterizing the most common CT-patterns of pulmonary disease. Eur J Radiol 2013; 82: e142-e150.

Castaldi PJ, San José Estépar R, Mendoza CS, et al. Distinct quantitative computed tomography emphysema patterns are associated with physiology and function in smokers. Am J Respir Crit Care Med 2013; 188: 1083-1090.

Coxson HO, Leipsic J, Parraga G, et al. Using pulmonary imaging to move COPD beyond FEV1. Am J Respir Crit Care Med 2014; 190: 135-144.

de Torres JP, Marín JM, Casanova C, et al. Lung cancer in patients with chronic obstructive pulmonary disease - incidence and predicting factors. Am J Respir Crit Care Med 2011; 184: 913-919.

Hardie JA, Buist AS, Vollmer WM, et al. Risk of over-diagnosis of COPD in asymptomatic elderly never-smokers. Eur Respir J 2002; 20: 1117-1122.

Cerveri I, Corsico AG, Accordini S, et al. Underestimation of airflow obstruction among young adults using FEV1/FVC $<70 \%$ as a fixed cut-off: a longitudinal evaluation of clinical and functional outcomes. Thorax 2008; 63: $1040-1045$.

Bhatt SP, Sieren JC, Dransfield MT, et al. COPDGene Investigators. Comparison of spirometric thresholds in diagnosing smoking-related airflow obstruction. Thorax 2014; 69: 409-414.

Carlsson AC, Wändell P, Ösby U, et al. High prevalence of diagnosis of diabetes, depression, anxiety, hypertension, asthma and COPD in the total population of Stockholm, Sweden - a challenge for public health. BMC Public Health 2013; 13: 670-678.

Bridevaux PO, Gerbase MW, Probst-Hensch NM, et al. Long-term decline in lung function, utilisation of care and quality of life in modified GOLD stage 1 COPD. Thorax 2008; 63: 768-774.

U.S. Preventive Services Task Force. Screening for chronic obstructive pulmonary disease using spirometry: U.S. Preventive Services Task Force recommendation statement. Ann Intern Med 2008; 148: 529-534.

Ferrer M, Alonso J, Morera J, et al. The Quality of Life of Chronic Obstructive Pulmonary Disease Study Group. Chronic obstructive pulmonary disease stage and health-related quality of life. Ann Intern Med 1997; 127: 1072-1079.

Friedman M, Serby CW, Menjoge SS, et al. Pharmacoeconomic evaluation of a combination of ipratropium plus albuterol compared with ipratropium alone and albuterol alone in COPD. Chest 1999; 115: 635-641.

Burge PS, Calverley PM, Jones PW, et al. Randomised, double blind, placebo controlled study of fluticasone propionate in patients with moderate to severe chronic obstructive pulmonary disease: the ISOLDE trial. $B M J$ 2000; 320: 1297-1303.

Dewan NA, Rafique S, Kanwar B, et al. Acute exacerbation of COPD: factors associated with poor treatment outcome. Chest 2000; 117: 662-671.

Anthonisen NR, Wright EC, Hodgkin JE. Prognosis in chronic obstructive pulmonary disease. Am Rev Respir Dis 1986; 133: 14-20.

Celli BR, Halbert RJ, Isonaka S, et al. Population impact of different definitions of airway obstruction. Eur Respir J 2003; 22: 268-273.

Parshall MB, Schwartzstein RM, Adams L, et al. American Thoracic Society Committee on Dyspnea. An official American Thoracic Society statement: update on the mechanisms, assessment, and management of dyspnea. Am J Respir Crit Care Med 2012; 185: 435-452.

Schols AM, Slangen J, Volovics L, et al. Weight loss is a reversible factor in the prognosis of chronic obstructive pulmonary disease. Am J Respir Crit Care Med 1998; 157: 1791-1797.

Landbo C, Prescott E, Lange P, et al. Prognostic value of nutritional status in chronic obstructive pulmonary disease. Am J Respir Crit Care Med 1999; 160: 1856-1861.

Mahler DA, Ward J, Waterman LA, et al. Patient-reported dyspnea in COPD reliability and association with stage of disease. Chest 2009; 136: 1473-1479.

Nishimura K, Izumi T, Tsukino M, et al. Dyspnea is a better predictor of 5-year survival than airway obstruction in patients with COPD. Chest 2002; 121: 1434-1440.

Garcia-Aymerich J, Lange P, Benet M, et al. Regular physical activity reduces hospital admission and mortality in chronic obstructive pulmonary disease: a population based cohort study. Thorax 2006; 61: 772-778.

Celli BR, Cote CG, Marin JM, et al. The body-mass index, airflow obstruction, dyspnea, and exercise capacity index in chronic obstructive pulmonary disease. N Engl J Med 2004; 350: 1005-1012.

Cote CG, Pinto-Plata VM, Marin JM, et al. The modified BODE index: validation with mortality in COPD. Eur Respir J 2008; 32: 1269-1274.

Soler-Cataluña JJ, Martínez-García MA, Sánchez LS, et al. Severe exacerbations and BODE index: two independent risk factors for death in male COPD patients. Respir Med 2009; 103: 692-699.

Marin JM, Alfageme I, Almagro P, et al. Multicomponent indices to predict survival in COPD: the COCOMICS study. Eur Respir J 2013; 42: 323-332.

Celli BR, Locantore N, Yates J, et al. ECLIPSE Investigators. Inflammatory biomarkers improve clinical prediction of mortality in chronic obstructive pulmonary disease. Am J Respir Crit Care Med 2012; 185: 1065-1072. 
Puhan MA, Garcia-Aymerich J, Frey M, et al. Expansion of the prognostic assessment of patients with chronic obstructive pulmonary disease: the updated BODE index and the ADO index. Lancet 2009; 374: 704-711.

Jones RC, Donaldson GC, Chavannes NH, et al. Derivation and validation of a composite index of severity in chronic obstructive pulmonary disease: the DOSE Index. Am J Respir Crit Care Med 2009; 180: 1189-1195.

Almagro P, Soriano JB, Cabrera FJ, et al. Working Group on COPD, Spanish Society of Internal Medicine. Shortand medium-term prognosis in patients hospitalized for COPD exacerbation: the CODEX index. Chest 2014; 145: 972-980.

Lange P, Marott JL, Vestbo J, et al. Prediction of the clinical course of chronic obstructive pulmonary disease, using the new GOLD classification: a study of the general population. Am J Respir Crit Care Med 2012; 186: 975-981.

Soriano JB, Alfageme I, Almagro P, et al. Distribution and prognostic validity of the new Global Initiative for Chronic Obstructive Lung Disease grading classification. Chest 2013; 143: 694-702.

Johannessen A, Nilsen RM, Storebø M, et al. Comparison of 2011 and 2007 Global Initiative for Chronic Obstructive Lung Disease guidelines for predicting mortality and hospitalization. Am J Respir Crit Care Med 2013; 188: 51-59.

Divo M, Cote C, de Torres JP, et al. BODE Collaborative Group. Comorbidities and risk of mortality in patients with chronic obstructive pulmonary disease. Am J Respir Crit Care Med 2012; 186: 155-161.

Agustí A, Barberà JA, Wouters EFM, et al. Lungs, bone marrow, and adipose tissue. A network approach to the pathobiology of chronic obstructive pulmonary disease. Am J Respir Crit Care Med 2013; 188: 1396-1406.

Donaldson GC, Seemungal TAR, Bhowmik A, et al. Relationship between exacerbation frequency and lung function decline in chronic obstructive pulmonary disease. Thorax 2002; 57: 847-852.

Vestbo J, Edwards LD, Scanlon PD, et al. ECLIPSE Investigators. Changes in forced expiratory volume in 1 second over time in COPD. N Engl J Med 2011; 365: 1184-1192.

Agusti A, Calverley PM, Celli B, et al. Evaluation of COPD Longitudinally to Identify Predictive Surrogate Endpoints (ECLIPSE) investigators. Characterisation of COPD heterogeneity in the ECLIPSE cohort. Respir Res 2010; 11: 122-136.

Freimer N, Sabatti C. The human phenome project. Nat Genet 2003; 34: 15-21.

Am J A Austi A, Calverley PM, et al. Chron

Drazen JM, Fabbri LM. Ageing and multimorbidity. Eur Respir J 2014; 44: 557.

Faner R, Cruz T, López-Giraldo A, et al. Network medicine, multimorbidity and the lung in the elderly. Eur Respir J 2014; 44: 775-788.

Divo MJ, Martinez CH, Mannino DM. Ageing and the epidemiology of multimorbidity. Eur Respir J 2014; 44 1055-1068.

Patel AR, Donaldson GC, Mackay AJ, et al. The impact of ischemic heart disease on symptoms, health status, and exacerbations in patients with COPD. Chest 2012; 141: 851-857.

Mannino DM, Thorn D, Swensen A, et al. Prevalence and outcomes of diabetes, hypertension and cardiovascular disease in COPD. Eur Respir J 2008; 32: 962-969.

Wilson DO, Leader JK, Fuhrman CR, et al. Quantitative computed tomography analysis, airflow obstruction, and lung cancer in the Pittsburgh lung screening study. J Thorac Oncol 2011; 6: 1200-1205.

Calverley PM, Anderson JA, Celli B, et al. TORCH investigators. Salmeterol and fluticasone propionate and survival in chronic obstructive pulmonary disease. N Engl J Med 2007; 356: 775-789.

Vanfleteren LE, Spruit MA, Groenen M, et al. Clusters of comorbidities based on validated objective measurements and systemic inflammation in patients with chronic obstructive pulmonary disease. Am J Respir Crit Care Med 2013; 187: 728-735.

Roca M, Verduri A, Corbetta L, et al. Mechanisms of acute exacerbation of respiratory symptoms in chronic obstructive pulmonary disease. Eur J Clin Invest 2013; 43: 510-521.

Donaldson GC, Hurst JR, Smith CJ, et al. Increased risk of myocardial infarction and stroke following exacerbation of COPD. Chest 2010; 137: 1091-1097.

Bowler RP, Kim V, Regan E, et al. COPDGene Investigators. Prediction of acute respiratory disease in current and former smokers with and without COPD. Chest 2014; 146: 941-950.

Tan WC, Bourbeau J, Hernandez P, et al. CanCOLD Collaborative Research Group. Exacerbation-like respiratory symptoms in individuals without chronic obstructive pulmonary disease: results from a population-based study. Thorax 2014; 69: 709-717.

Marin JM, Soriano JB, Carrizo SJ, et al. Outcomes in patients with chronic obstructive pulmonary disease and obstructive sleep apnea: the overlap syndrome. Am J Respir Crit Care Med 2010; 182: 325-331.

Repine JE, Bast A, Lankhorst I. Oxidative Stress Study Group. Oxidative stress in chronic obstructive pulmonary disease. Am J Respir Crit Care Med 1997; 156: 341-357.

Tzortzaki EG, Siafakas NM. A hypothesis for the initiation of COPD. Eur Respir J 2009; 34: 310-315.

Sethi S, Murphy TF. Infection in the pathogenesis and course of chronic obstructive pulmonary disease. $N$ Engl $J$ Med 2008; 359: 2355-2365.

Pragman AA, Kim HB, Reilly CS, et al. The lung microbiome in moderate and severe chronic obstructive pulmonary disease. PLoS ONE 2012; 7: e47305.

Cosio MG, Saetta M, Agusti A. Immunologic aspects of chronic obstructive pulmonary disease. N Engl J Med 2009; 360: 2445-2454.

Demedts IK, Demoor T, Bracke KR, et al. Role of apoptosis in the pathogenesis of COPD and pulmonary emphysema. Respir Res 2006; 7: 53. idiopathic pulmonary fibrosis. Am J Respir Crit Care Med 2012; 186: 306-313. pulmonary disease: basic considerations for future drug development. Curr Drug Metab 2008; 9: 661-667.

Rab A, Rowe SM, Raju SV, et al. Cigarette smoke and CFTR: implications in the pathogenesis of COPD. Am J Physiol Lung Cell Mol Physiol 2013; 305: L530-L541. 
Saetta M, Di Stefano A, Turato G, et al. CD8+ T-lymphocytes in peripheral airways of smokers with chronic obstructive pulmonary disease. Am J Respir Crit Care Med 1998; 157: 822-826.

Rennard SI. Inflammation and repair processes in chronic obstructive pulmonary disease. Am J Respir Crit Care Med 1999; 160: S12-S16.

Peinado VI, Barberá JA, Abate P, et al. Inflammatory reaction in pulmonary muscular arteries of patients with mild chronic obstructive pulmonary disease. Am J Respir Crit Care Med 1999; 159: 1605-1611.

Rodriguez-Roisin R, MacNee W. Pathophysiology of chronic obstructive pulmonary disease. Eur Respir Monogr 1998; 3: 107-126.

O'Shaughnessy TC, Ansari TW, Barnes NC, et al. Inflammation in bronchial biopsies of subjects with chronic bronchitis: inverse relationship of CD8+ T lymphocytes with FEV1. Am J Respir Crit Care Med 1997; 155: 852-857. Matsuba K, Wright JL, Wiggs BR, et al. The changes in airways structure associated with reduced forced expiratory volume in one second. Eur Respir J 1989; 2: 834-839.

O'Donnell DE, Revill SM, Webb KA. Dynamic hyperinflation and exercise intolerance in chronic obstructive pulmonary disease. Am J Respir Crit Care Med 2001; 164: 770-777.

Jha P, Peto R. Global effects of smoking, of quitting, and of taxing tobacco. N Engl J Med 2014; 370: 60-68. Anthonisen NR, Connett JE, Murray RP. Smoking and lung function of Lung Health Study participants after 11 years. Am J Respir Crit Care Med 2002; 166: 675-679.

Parkes G, Greenhalgh T, Griffin M, et al. Effect on smoking quit rate of telling patients their lung age: the Step2quit randomised controlled trial. BMJ 2008; 336: 598-600.

Bednarek M, Gorecka D, Wielgomas J, et al. Smokers with airway obstruction are more likely to quit smoking. Thorax 2006; 61: 869-873.

Stratelis G, Mölstad S, Jakobsson P, et al. The impact of repeated spirometry and smoking cessation advice on smokers with mild COPD. Scand J Prim Health Care 2006; 24: 133-139.

Kotz D, Wesseling G, Huibers MJH, et al. Efficacy of confronting smokers with airflow limitation for smoking cessation. Eur Respir J 2009; 33: 754-762.

Jiménez-Ruiz CA, Masa F, Miravitlles M, et al. Smoking characteristics: differences in attitudes and dependence between healthy smokers and smokers with COPD. Chest 2001; 119: 1365-1370. a double-blind, placebo-controlled, randomised trial. Lancet 2001; 357: 1571-1575.

Tashkin DP, Rennard S, Hays JT, et al. Effects of varenicline on smoking cessation in patients with mild to moderate COPD: a randomized controlled trial. Chest 2011; 139: 591-599.

Tønnesen P, Mikkelsen K, Bremann L. Nurse-conducted smoking cessation in patients with COPD using nicotine sublingual tablets and behavioral support. Chest 2006; 130: 334-342.

Wagena EJ, van der Meer RM, Ostelo RJ, et al. The efficacy of smoking cessation strategies in people with chronic obstructive pulmonary disease: results from a systematic review. Respir Med 2004; 98: 805-815.

Wilson I. Depression in the patient with COPD. Int J Chron Obstruct Pulmon Dis 2006; 1: 61-64.

Rigotti NA, Pipe AL, Benowitz NL, et al. Efficacy and safety of varenicline for smoking cessation in patients with cardiovascular disease: a randomized trial. Circulation 2010; 121: 221-229.

Kuehn BM. Updated US smoking cessation guideline advises counseling, combining therapies. JAMA 2008; 299: 2736.

Shah SD, Wilken LA, Winkler SR, et al. Systematic review and meta-analysis of combination therapy for smoking cessation. J Am Pharm Assoc (2003) 2008; 48: 659-665.

Steinberg MB, Greenhaus S, Schmelzer AC, et al. Triple-combination pharmacotherapy for medically ill smokers: a randomized trial. Ann Intern Med 2009; 150: 447-454.

Piper ME, Smith SS, Schlam TR, et al. A randomized placebo-controlled clinical trial of 5 smoking cessation pharmacotherapies. Arch Gen Psychiatry 2009; 66: 1253-1262.

Ellerbeck EF, Mahnken JD, Cupertino AP, et al. Effect of varying levels of disease management on smoking cessation: a randomized trial. Ann Intern Med 2009; 150: 437-446.

Fiore MC, Jaen CR, Baker TB, et al. Treating Tobacco Use and Dependence: 2008 Update. Clinical Practice Guidelines. Rockville, US Department of Health and Human Services, 2008.

Crowley TJ, Macdonald MJ, Walter MI. Behavioral anti-smoking trial in chronic obstructive pulmonary disease patients. Psychopharmacology (Berl) 1995; 119: 193-204.

Etter J-F, Bullen C, Flouris AD, et al. Electronic nicotine delivery systems: a research agenda. Tob Control 2011; 20: $243-248$

Etter J-F, Bullen C. Electronic cigarette: users profile, utilization, satisfaction and perceived efficacy. Addiction 2011; 106: 2017-2028.

Goniewicz ML, Lingas EO, Hajek P. Patterns of electronic cigarette use and user beliefs about their safety and benefits: an internet survey. Drug Alcohol Rev 2013; 32: 133-140.

Bertholon JF, Becquemin MH, Annesi-Maesano I, et al. Electronic cigarettes: a short review. Respiration 2013; 86: 433-438.

4 Schraufnagel DE, Blasi F, Drummond MB, et al. Forum of International Respiratory Societies. Electronic cigarettes: a position statement of the forum of international respiratory societies. Am J Respir Crit Care Med 2014; 190: 611-618.

Buist AS, Sexton GJ, Nagy JM, et al. The effect of smoking cessation and modification on lung function. Am Rev Respir Dis 1976; 114: 115-122.

Jiménez-Ruiz C, Solano S, Viteri SA, et al. Harm reduction-a treatment approach for resistant smokers with tobacco-related symptoms. Respiration 2002; 69: 452-455.

Rennard SI, Daughton D, Fujita J, et al. Short-term smoking reduction is associated with reduction in measures of lower respiratory tract inflammation in heavy smokers. Eur Respir J 1990; 3: 752-759.

Simmons MS, Connett JE, Nides MA, et al. Smoking reduction and the rate of decline in FEV1: results from the Lung Health Study. Eur Respir J 2005; 25: 1011-1017.

Hughes JR, Carpenter MJ. Does smoking reduction increase future cessation and decrease disease risk? A qualitative review. Nicotine Tob Res 2006; 8: 739-749. 
120 Boyle R, Solberg L, Fiore M. Use of electronic health records to support smoking cessation. Cochrane Database Syst Rev 2011; 12: CD008743.

121 Tetrault JM, Crothers K, Moore BA, et al. Effects of marijuana smoking on pulmonary function and respiratory complications: a systematic review. Arch Intern Med 2007; 167: 221-228.

122 Tashkin DP, Celli B, Senn S, et al. UPLIFT Study Investigators. A 4-year trial of tiotropium in chronic obstructive pulmonary disease. N Engl J Med 2008; 359: 1543-1554.

123 Jenkins CR, Jones PW, Calverley PM, et al. Efficacy of salmeterol/fluticasone propionate by GOLD stage of chronic obstructive pulmonary disease: analysis from the randomised, placebo-controlled TORCH study. Respir Res 2009; 10: 59.

124 Burgel PR, Paillasseur JL, Dusser D, et al. UPLIFT ${ }^{\star}$ Study Investigators. Tiotropium might improve survival in subjects with COPD at high risk of mortality. Respir Res 2014; 15: 64.

125 Celli BR, Thomas NE, Anderson JA, et al. Effect of pharmacotherapy on rate of decline of lung function in chronic obstructive pulmonary disease: results from the TORCH study. Am J Respir Crit Care Med 2008; 178: 332-338.

126 Decramer M, Celli B, Kesten S, et al. UPLIFT investigators. Effect of tiotropium on outcomes in patients with moderate chronic obstructive pulmonary disease (UPLIFT): a prespecified subgroup analysis of a randomised controlled trial. Lancet 2009; 374: 1171-1178.

127 Burgel PR, Paillasseur JL, Peene B, et al. Two distinct chronic obstructive pulmonary disease (COPD) phenotypes are associated with high risk of mortality. PLOS ONE 2012; 7: e51048.

128 Bateman ED, Feldman C, O'Brien J, et al. Guideline for the management of chronic obstructive pulmonary disease (COPD): 2004 revision. S Afr Med J 2004; 94: 559-575.

129 Wedzicha JA, Decramer M, Seemungal TA. The role of bronchodilator treatment in the prevention of exacerbations of COPD. Eur Respir J 2012; 40: 1545-1554.

130 Han MK, Tayob N, Murray S, et al. Predictors of chronic obstructive pulmonary disease exacerbation reduction in response to daily azithromycin therapy. Am J Respir Crit Care Med 2014; 189: 1503-1508.

131 Chong J, Karner C, Poole P. Tiotropium versus long-acting beta-agonists for stable chronic obstructive pulmonary disease. Cochrane Database Syst Rev 2012; 9: CD009157.

132 Rabe KF, Fabbri LM, Israel E, et al. Effect of ADRB2 polymorphism on the efficacy of salmeterol and tiotropium in preventing COPD exacerbations: a prespecified substudy of the POET-COPD trial. Lancet Respir Med 2014; 2: 44-53.

133 Decramer ML, Chapman KR, Dahl R, et al. INVIGORATE investigators. Once-daily indacaterol versus tiotropium for patients with severe chronic obstructive pulmonary disease (INVIGORATE): a randomised, blinded, parallel-group study. Lancet Respir Med 2013; 1: 524-533.

134 Calverley PM, Stockley RA, Seemungal TA, et al. Investigating New Standards for Prophylaxis in Reduction of Exacerbations (INSPIRE) Investigators. Reported pneumonia in patients with COPD: findings from the INSPIRE study. Chest 2011; 139: 505-512

135 Crim C, Calverley PM, Anderson JA, et al. Pneumonia risk in COPD patients receiving inhaled corticosteroids alone or in combination: TORCH study results. Eur Respir J 2009; 34: 641-647.

136 Wedzicha JA, Calverley PM, Seemungal TA, et al. INSPIRE Investigators. The prevention of chronic obstructive pulmonary disease exacerbations by salmeterol/fluticasone propionate or tiotropium bromide. Am J Respir Crit Care Med 2008; 177: 19-26.

137 Aaron SD, Vandemheen KL, Fergusson D, et al. Canadian Thoracic Society/Canadian Respiratory Clinical Research Consortium. Tiotropium in combination with placebo, salmeterol, or fluticasone-salmeterol for treatment of chronic obstructive pulmonary disease: a randomized trial. Ann Intern Med 2007; 146: 545-555.

138 Wedzicha JA, Decramer M, Ficker JH, et al. Analysis of chronic obstructive pulmonary disease exacerbations with the dual bronchodilator QVA149 compared with glycopyrronium and tiotropium (SPARK): a randomised, double-blind, parallel-group study. Lancet Respir Med 2013; 1: 199-209.

139 Short PM, Williamson PA, Elder DH, et al. The impact of tiotropium on mortality and exacerbations when added to inhaled corticosteroids and long-acting $\beta$-agonist therapy in COPD. Chest 2012; 141: 81-86.

140 Jung KS, Park HY, Park SY, et al. Korean Academy of Tuberculosis and Respiratory Diseases study group; Korea Chronic Obstructive Pulmonary Disease study group. Comparison of tiotropium plus fluticasone propionate/ salmeterol with tiotropium in COPD: a randomized controlled study. Respir Med 2012; 106: 382-389.

141 Magnussen H, Disse B, Rodriguez-Roisin R, et al. WISDOM Investigators. Withdrawal of inhaled glucocorticoids and exacerbations of COPD. N Engl J Med 2014; 371: 1285-1294.

142 Dodd JW, Hogg L, Nolan J, et al. The COPD assessment test (CAT): response to pulmonary rehabilitation. A multicentre, prospective study. Thorax 2011; 66: 425-429.

143 Jones PW, Harding G, Berry P, et al. Development and first validation of the COPD Assessment Test. Eur Respir J 2009; 34: 648-654.

144 Jones PW, Harding G, Wiklund I, et al. Tests of the responsiveness of the COPD assessment test following acute exacerbation and pulmonary rehabilitation. Chest 2012; 142: 134-140.

145 Vestbo J, Anderson JA, Calverley PM, et al. Adherence to inhaled therapy, mortality and hospital admission in COPD. Thorax 2009; 64: 939-943.

146 Toy EL, Beaulieu NU, McHale JM, et al. Treatment of COPD: relationships between daily dosing frequency, adherence, resource use, and costs. Respir Med 2011; 105: 435-441.

147 Barnestein-Fonseca P, Leiva-Fernández J, Vidal-España F, et al. Efficacy and safety of a multifactor intervention to improve therapeutic adherence in patients with chronic obstructive pulmonary disease (COPD): protocol for the ICEPOC study. Trials 2011; 12: 40.

148 Melani AS, Bonavia M, Cilenti V, et al. Gruppo Educazionale Associazione Italiana Pneumologi Ospedalieri. Inhaler mishandling remains common in real life and is associated with reduced disease control. Respir Med 2011; 105: 930-938.

149 Vincken W, Dekhuijzen PR, Barnes P. ADMIT Group. The ADMIT series - Issues in inhalation therapy. 4) How to choose inhaler devices for the treatment of COPD. Prim Care Respir J 2010; 19: 10-20.

150 Laube BL, Janssens HM, de Jongh FHC, et al. European Respiratory Society; International Society for Aerosols in Medicine. What the pulmonary specialist should know about the new inhalation therapies. Eur Respir J 2011; 37: $1308-1331$. 
Sevenoaks MJ, Stockley RA. Chronic Obstructive Pulmonary Disease, inflammation and co-morbidity-a common inflammatory phenotype? Respir Res 2006; 7: 70.

Barnes PJ. New anti-inflammatory targets for chronic obstructive pulmonary disease. Nat Rev Drug Discov 2013; 12: 543-559.

Brusselle GG, Joos GF, Bracke KR. New insights into the immunology of chronic obstructive pulmonary disease. Lancet 2011; 378: 1015-1026.

Rennard SI, Fogarty C, Kelsen S, et al. COPD Investigators. The safety and efficacy of infliximab in moderate to severe chronic obstructive pulmonary disease. Am J Respir Crit Care Med 2007; 175: 926-934.

Brightling CE, Bleecker ER, Panettieri RA Jr, et al. Benralizumab for chronic obstructive pulmonary disease and sputum eosinophilia: a randomized, double-blind, placebo-controlled, phase 2a study. Lancet Respir Med 2014; 2: 891-901.

Chong J, Poole P, Leung B, et al. Phosphodiesterase 4 inhibitors for chronic obstructive pulmonary disease. Cochrane Database Syst Rev 2011; 5: CD002309.

Powrie DJ, Wilkinson TM, Donaldson GC, et al. Effect of tiotropium on sputum and serum inflammatory markers and exacerbations in COPD. Eur Respir J 2007; 30: 472-478.

Lomas DA, Lipson DA, Miller BE, et al. Losmapimod Study Investigators. An oral inhibitor of p38 MAP kinase reduces plasma fibrinogen in patients with chronic obstructive pulmonary disease. J Clin Pharmacol 2012; 52: $416-424$.

Watz H, Barnacle H, Hartley BF, et al. Efficacy and safety of the p38 MAPK inhibitor losmapimod for patients with chronic obstructive pulmonary disease: a randomised, double-blind, placebo-controlled trial. Lancet Respir Med 2014; 2: 63-72.

Barnes PJ, Adcock IM. Glucocorticoid resistance in inflammatory diseases. Lancet 2009; 373: 1905-1917.

Bafadhel M, Davies L, Calverley PM, et al. Blood eosinophil guided prednisolone therapy for exacerbations of COPD: a further analysis. Eur Respir J 2014; 44: 789-791.

Bafadhel M, McKenna S, Terry S, et al. Blood eosinophils to direct corticosteroid treatment of exacerbations of chronic obstructive pulmonary disease: a randomized placebo-controlled trial. Am J Respir Crit Care Med 2012; 186: $48-55$.

Ortega H, Li H, Suruki R, et al. Cluster analysis and characterization of response to mepolizumab. A step closer to personalized medicine for patients with severe asthma. Ann Am Thorac Soc 2014; 11: 1011-1017.

Pavord ID, Korn S, Howarth P, et al. Mepolizumab for severe eosinophilic asthma (DREAM): a multicentre, double-blind, placebo-controlled trial. Lancet 2012; 380: 651-659.

Hodge S, Hodge G, Jersmann H, et al. Azithromycin improves macrophage phagocytic function and expression of mannose receptor in chronic obstructive pulmonary disease. Am J Respir Crit Care Med 2008; 178: 139-148.

Yamaya M, Azuma A, Takizawa H, et al. Macrolide effects on the prevention of COPD exacerbations. Eur Respir J 2012; 40: 485-494.

Albert RK, Connett J, Bailey WC, et al. COPD Clinical Research Network. Azithromycin for prevention of exacerbations of COPD. N Engl J Med 2011; 365: 689-698.

Seemungal TA, Wilkinson TM, Hurst JR, et al. Long-term erythromycin therapy is associated with decreased chronic obstructive pulmonary disease exacerbations. Am J Respir Crit Care Med 2008; 178: 1139-1147.

Ray WA, Murray KT, Hall K, et al. Azithromycin and the risk of cardiovascular death. N Engl J Med 2012; 366: 1881-1890.

Ray WA, Murray KT, Meredith S, et al. Oral erythromycin and the risk of sudden death from cardiac causes. N Engl J Med 2004; 351: 1089-1096.

Svanström H, Pasternak B, Hviid A. Use of azithromycin and death from cardiovascular causes. $N$ Engl J Med 2013; 368: 1704-1712.

Sethi S, Jones PW, Theron MS, et al. PULSE Study group. Pulsed moxifloxacin for the prevention of exacerbations of chronic obstructive pulmonary disease: a randomized controlled trial. Respir Res 2010; 11: 10.

Marin L, Colombo P, Bebawy M, et al. Chronic obstructive pulmonary disease: patho-physiology, current methods of treatment and the potential for simvastatin in disease management. Expert Opin Drug Deliv 2011; 8: 1205-1220.

Young RP, Hopkins R, Eaton TE. Potential benefits of statins on morbidity and mortality in chronic obstructive pulmonary disease: a review of the evidence. Postgrad Med J 2009; 85: 414-421.

Bando M, Miyazawa T, Shinohara $\mathrm{H}$, et al. An epidemiological study of the effects of statin use on airflow limitation in patients with chronic obstructive pulmonary disease. Respirology 2012; 17: 493-498.

Bartziokas K, Papaioannou AI, Minas M, et al. Statins and outcome after hospitalization for COPD exacerbation: a prospective study. Pulm Pharmacol Ther 2011; 24: 625-631.

Janda S, Park K, FitzGerald JM, et al. Statins in COPD: a systematic review. Chest 2009; 136: 734-743.

Dobler CC, Wong KK, Marks GB. Associations between statins and COPD: a systematic review. BMC Pulm Med 2009; 9: 32.

Lee TM, Chen CC, Shen HN, et al. Effects of pravastatin on functional capacity in patients with chronic obstructive pulmonary disease and pulmonary hypertension. Clin Sci (Lond) 2009; 116: 497-505.

80 Criner GJ, Connett JE, Aaron SD, et al. COPD Clinical Research Network; Canadian Institutes of Health Research. Simvastatin for the prevention of exacerbations in moderate-to-severe COPD. N Engl J Med 2014; 370: 2201-2210.

81 Price LC, Lowe D, Hosker HS, et al. British Thoracic Society and the Royal College of Physicians Clinical Effectiveness Evaluation Unit (CEEu). UK National COPD Audit 2003: impact of hospital resources and organisation of care on patient outcome following admission for acute COPD exacerbation. Thorax 2006; 61: $837-842$.

2 Rutten FH, Zuithoff NP, Hak E, et al. Beta-blockers may reduce mortality and risk of exacerbations in patients with chronic obstructive pulmonary disease. Arch Intern Med 2010; 170: 880-887.

Nussbaumer-Ochsner Y, Rabe KF. Systemic manifestations of COPD. Chest 2011; 139: 165-173.

Spruit MA, Singh SJ, Garvey C, et al. ATS/ERS Task Force on Pulmonary Rehabilitation. An official American Thoracic Society/European Respiratory Society statement: key concepts and advances in pulmonary rehabilitation. Am J Respir Crit Care Med 2013; 188: e13-e64. 
185 Vieira DS, Maltais F, Bourbeau J. Home-based pulmonary rehabilitation in chronic obstructive pulmonary disease patients. Curr Opin Pulm Med 2010; 16: 134-143.

186 Maltais F, Bourbeau J, Shapiro S, et al. Chronic Obstructive Pulmonary Disease Axis of Respiratory Health Network, Fonds de recherche en santé du Québec. Effects of home-based pulmonary rehabilitation in patients with chronic obstructive pulmonary disease: a randomized trial. Ann Intern Med 2008; 149: 869-878.

187 van Wetering CR, Hoogendoorn M, Mol SJ, et al. Short- and long-term efficacy of a community-based COPD management programme in less advanced COPD: a randomised controlled trial. Thorax 2010; 65: 7-13.

188 van Wetering CR, Hoogendoorn M, Broekhuizen R, et al. Efficacy and costs of nutritional rehabilitation in muscle-wasted patients with chronic obstructive pulmonary disease in a community-based setting: a prespecified subgroup analysis of the INTERCOM trial. J Am Med Dir Assoc 2010; 11: 179-187.

189 Puhan MA, Gimeno-Santos E, Scharplatz M, et al. Pulmonary rehabilitation following exacerbations of chronic obstructive pulmonary disease. Cochrane Database Syst Rev 2011; 10: CD005305.

190 Casaburi R, Kukafka D, Cooper CB, et al. Improvement in exercise tolerance with the combination of tiotropium and pulmonary rehabilitation in patients with COPD. Chest 2005; 127: 809-817.

191 Report of the Medical Research Council Working Party. Long term domiciliary oxygen therapy in chronic hypoxic cor pulmonale complicating chronic bronchitis and emphysema. Lancet 1981; 1: 681-686.

192 Nocturnal Oxygen Therapy Trial Group. Continuous or nocturnal oxygen therapy in hypoxemic chronic obstructive lung disease: a clinical trial. Ann Intern Med 1980; 93: 391-398.

193 Górecka D, Gorzelak K, Sliwiński P, et al. Effect of long-term oxygen therapy on survival in patients with chronic obstructive pulmonary disease with moderate hypoxaemia. Thorax 1997; 52: 674-679.

194 Chaouat A, Weitzenblum E, Kessler R, et al. A randomized trial of nocturnal oxygen therapy in chronic obstructive pulmonary disease patients. Eur Respir J 1999; 14: 1002-1008.

195 Petty TL, Stanford RE, Neff TA. Continuous oxygen therapy in chronic airway obstruction. Observations on possible oxygen toxicity and survival. Ann Intern Med 1971; 75: 361-367.

196 West GA, Primeau P. Nonmedical hazards of long-term oxygen therapy. Respir Care 1983; 28: 906-912.

197 Murabit A, Tredget EE. Review of burn injuries secondary to home oxygen. J Burn Care Res 2012; 33: 212-217.

198 Brochard L, Mancebo J, Wysocki M, et al. Noninvasive ventilation for acute exacerbations of chronic obstructive pulmonary disease. $N$ Engl J Med 1995; 333: 817-822.

199 Bott J, Carroll MP, Conway JH, et al. Randomised controlled trial of nasal ventilation in acute ventilatory failure due to chronic obstructive airways disease. Lancet 1993; 341: 1555-1557.

200 Kramer N, Meyer TJ, Meharg J, et al. Randomized, prospective trial of noninvasive positive pressure ventilation in acute respiratory failure. Am J Respir Crit Care Med 1995; 151: 1799-1806.

201 Plant PK, Owen JL, Elliott MW. Early use of non-invasive ventilation for acute exacerbations of chronic obstructive pulmonary disease on general respiratory wards: a multicentre randomised controlled trial. Lancet 2000; 355: 1931-1935.

202 Nava S, Hill N. Non-invasive ventilation in acute respiratory failure. Lancet 2009; 374: 250-259.

203 Bhatt SP, Peterson MW, Wilson JS, et al. Noninvasive positive pressure ventilation in subjects with stable COPD: a randomized trial. Int J Chron Obstruct Pulmon Dis 2013; 8: 581-589.

204 Lamia B, Cuvelier A, Benichou J, et al. Bénéfices de la ventilation non invasive à domicile au décours d'une insuffisance respiratoire aiguë hypercapnique chez les patients BPCO. Étude contrôlée randomisée multicentrique. Étude Non Invasive Ventilation in Obstructive Lung Disease (Nivold) [A multi-centre randomised controlled trial of domiciliary non-invasive ventilation vs long-term oxygen therapy in survivors of acute hypercapnic respiratory failure due to COPD. Non-invasive ventilation in obstructive lung disease (NIVOLD) study]. Rev Mal Respir 2012; 29: 1141-1148.

205 Clini E, Sturani C, Rossi A, et al. Rehabilitation and Chronic Care Study Group, Italian Association of Hospital Pulmonologists (AIPO). The Italian multicentre study on noninvasive ventilation in chronic obstructive pulmonary disease patients. Eur Respir J 2002; 20: 529-538.

206 Struik FM, Sprooten RT, Kerstjen HA, et al. Nocturnal non-invasive ventilation in COPD patients with prolonged hypercapnia after ventilatory support for acute respiratory failure: a randomised, controlled, parallel-group study. Thorax 2014; 69: 826-834.

207 Struik FM, Lacasse Y, Goldstein RS, et al. Nocturnal noninvasive positive pressure ventilation in stable COPD: a systematic review and individual patient data meta-analysis. Respir Med 2014; 108: 329-337.

208 Kohnlein T, Windisch W, Kohler D, et al. Non-invasive positive pressure ventilation for the treatment of severe stable chronic obstructive pulmonary disease: a prospective, multicentre, randomised, controlled clinical trial. Lancet Respir Med 2014; 2: 698-705.

209 Meyers BF, Patterson GA. Chronic obstructive pulmonary disease. 10: Bullectomy, lung volume reduction surgery, and transplantation for patients with chronic obstructive pulmonary disease. Thorax 2003; 58: 634-638.

210 Fishman A, Martinez F, Naunheim K, et al. National Emphysema Treatment Trial Research Group. A randomized trial comparing lung-volume-reduction surgery with medical therapy for severe emphysema. $N$ Engl J Med 2003; 348: 2059-2073.

211 Ramsey SD, Berry K, Etzioni R, et al. National Emphysema Treatment Trial Research Group. Cost effectiveness of lung-volume-reduction surgery for patients with severe emphysema. N Engl J Med 2003; 348: 2092-2102.

212 Sciurba FC, Ernst A, Herth FJ, et al. VENT Study Research Group. A randomized study of endobronchial valves for advanced emphysema. N Engl J Med 2010; 363: 1233-1244.

213 Christie JD, Edwards LB, Kucheryavaya AY, et al. International Society of Heart and Lung Transplantation. The Registry of the International Society for Heart and Lung Transplantation: 29th adult lung and heart-lung transplant report-2012. J Heart Lung Transplant 2012; 31: 1073-1086.

214 Thabut G, Ravaud P, Christie JD, et al. Determinants of the survival benefit of lung transplantation in patients with chronic obstructive pulmonary disease. Am J Respir Crit Care Med 2008; 177: 1156-1163.

215 Lahzami S, Bridevaux PO, Soccal PM, et al. Survival impact of lung transplantation for COPD. Eur Respir J 2010; 36: 74-80.

216 Eskander A, Waddell TK, Faughnan ME, et al. BODE index and quality of life in advanced chronic obstructive pulmonary disease before and after lung transplantation. J Heart Lung Transplant 2011; 30: 1334-1341. 
217 Orens JB, Estenne M, Arcasoy S, et al. Pulmonary Scientific Council of the International Society for Heart and Lung Transplantation. International guidelines for the selection of lung transplant candidates: 2006 update - a consensus report from the Pulmonary Scientific Council of the International Society for Heart and Lung Transplantation. J Heart Lung Transplant 2006; 25: 745-755.

218 Thabut G, Christie JD, Ravaud P, et al. Survival after bilateral versus single lung transplantation for patients with chronic obstructive pulmonary disease: a retrospective analysis of registry data. Lancet 2008; 371: 744-751.

219 Wang Q, Rogers CA, Bonser RS, et al. UK Cardiothoracic Transplant Steering Group. Assessing the benefit of accepting a single lung offer now compared with waiting for a subsequent double lung offer. Transplantation 2011; 91: 921-926.

220 Munson JC, Christie JD, Halpern SD. The societal impact of single versus bilateral lung transplantation for chronic obstructive pulmonary disease. Am J Respir Crit Care Med 2011; 184: 1282-1288.

221 Schols AM, Gosker HR. The pathophysiology of cachexia in chronic obstructive pulmonary disease. Curr Opin Support Palliat Care 2009; 3: 282-287.

222 Mostert R, Goris A, Weling-Scheepers C, et al. Tissue depletion and health related quality of life in patients with chronic obstructive pulmonary disease. Respir Med 2000; 94: 859-867.

223 Creutzberg EC, Schols AMWJ, Bothmer-Quaedvlieg FCM, et al. Prevalence of an elevated resting energy expenditure in patients with chronic obstructive pulmonary disease in relation to body composition and lung function. Eur J Clin Nutr 1998; 52: 396-401.

224 Hallin R, Janson C, Arnardottir RH, et al. Relation between physical capacity, nutritional status and systemic inflammation in COPD. Clin Respir J 2011; 5: 136-142.

225 Collins PF, Stratton RJ, Elia M. Nutritional support in chronic obstructive pulmonary disease: a systematic review and meta-analysis. Am J Clin Nutr 2012; 95: 1385-1395.

226 Ferreira IM, Brooks D, Lacasse Y, et al. Nutritional support for individuals with COPD: a meta-analysis. Chest 2000; 117: 672-678.

227 Laveneziana P, Palange P. ERS Research Seminar Faculty. Physical activity, nutritional status and systemic inflammation in COPD. Eur Respir J 2012; 40: 522-529.

228 Hanson C, Rutten EP, Wouters EF, et al. Diet and vitamin D as risk factors for lung impairment and COPD. Transl Res 2013; 162: 219-236.

229 Bjerk SM, Edgington BD, Rector TS, et al. Supplemental vitamin D and physical performance in COPD: a pilot randomized trial. Int J Chron Obstruct Pulmon Dis 2013; 8: 97-104.

230 Bourbeau J, Julien M, Maltais F, et al. Chronic Obstructive Pulmonary Disease axis of the Respiratory Network Fonds de la Recherche en Santé du Québec. Reduction of hospital utilization in patients with chronic obstructive pulmonary disease: a disease-specific self-management intervention. Arch Intern Med 2003; 163: 585-591.

231 Hernandez C, Casas A, Escarrabill J, et al. CHRONIC project. Home hospitalisation of exacerbated chronic obstructive pulmonary disease patients. Eur Respir J 2003; 21: 58-67.

232 Garcia-Aymerich J, Hernandez C, Alonso A, et al. Effects of an integrated care intervention on risk factors of COPD readmission. Respir Med 2007; 101: 1462-1469.

233 Casas A, Troosters T, Garcia-Aymerich J, et al. members of the CHRONIC Project. Integrated care prevents hospitalisations for exacerbations in COPD patients. Eur Respir J 2006; 28: 123-130.

234 Rice KL, Dewan N, Bloomfield HE, et al. Disease management program for chronic obstructive pulmonary disease: a randomized controlled trial. Am J Respir Crit Care Med 2010; 182: 890-896.

235 Fan VS, Gaziano JM, Lew R, et al. A comprehensive care management program to prevent chronic obstructive pulmonary disease hospitalizations: a randomized, controlled trial. Ann Intern Med 2012; 156: 673-683.

236 Ram FS, Wedzicha JA, Wright J, et al. Hospital at home for patients with acute exacerbations of chronic obstructive pulmonary disease: systematic review of evidence. BMJ 2004; 329: 315.

237 Seemungal TA, Wedzicha JA. Integrated care: a new model for COPD management? Eur Respir J 2006; 28: 4-6.

238 Vontetsianos T, Giovas P, Katsaras T, et al. Telemedicine-assisted home support for patients with advanced chronic obstructive pulmonary disease: preliminary results after nine-month follow-up. J Telemed Telecare 2005; 11: 86-88.

239 Vitacca M, Bianchi L, Guerra A, et al. Tele-assistance in chronic respiratory failure patients: a randomised clinical trial. Eur Respir J 2009; 33: 411-418.

240 Sicotte C, Paré G, Morin S, et al. Effects of home telemonitoring to support improved care for chronic obstructive pulmonary diseases. Telemed J E Health 2011; 17: 95-103.

241 Pinnock H, Hanley J, McCloughan L, et al. Effectiveness of telemonitoring integrated into existing clinical services on hospital admission for exacerbation of chronic obstructive pulmonary disease: researcher blind, multicentre, randomised controlled trial. BMJ 2013; 347: f6070.

242 Knauft E, Nielsen EL, Engelberg RA, et al. Barriers and facilitators to end-of-life care communication for patients with COPD. Chest 2005; 127: 2188-2196.

$243 \mathrm{Au}$ DH, Udris EM, Fihn SD, et al. Differences in health care utilization at the end of life among patients with chronic obstructive pulmonary disease and patients with lung cancer. Arch Intern Med 2006; 166: 326-331.

244 Curtis JR, Engelberg RA, Nielsen EL, et al. Patient-physician communication about end-of-life care for patients with severe COPD. Eur Respir J 2004; 24: 200-205.

$245 \mathrm{Au} \mathrm{DH}$, Udris EM, Engelberg RA, et al. A randomized trial to improve communication about end-of-life care among patients with COPD. Chest 2012; 141: 726-735.

246 Claessens MT, Lynn J, Zhong Z, et al. Study to Understand Prognoses and Preferences for Outcomes and Risks of Treatments. Dying with lung cancer or chronic obstructive pulmonary disease: insights from SUPPORT. J Am Geriatr Soc 2000; 48, Suppl. 5: S146-S153.

247 White P, White S, Edmonds P, et al. Palliative care or end-of-life care in advanced chronic obstructive pulmonary disease: a prospective community survey. Br J Gen Pract 2011; 61: e362-e370.

248 Janssen DJ, Spruit MA, Uszko-Lencer NH, et al. Symptoms, comorbidities, and health care in advanced chronic obstructive pulmonary disease or chronic heart failure. J Palliat Med 2011; 14: 735-743.

249 Gott M, Gardiner C, Small N, et al. Barriers to advance care planning in chronic obstructive pulmonary disease. Palliat Med 2009; 23: 642-648. 
250 Janssen DJ, Curtis JR, Au DH, et al. Patient-clinician communication about end-of-life care for Dutch and US patients with COPD. Eur Respir J 2011; 38: 268-276.

251 Fleisher LA, Beckman JA, Brown KA, et al. American College of Cardiology/American Heart Association Task Force on Practice Guidelines (Writing Committee to Revise the 2002 Guidelines on Perioperative Cardiovascular Evaluation for Noncardiac Surgery); American Society of Echocardiography; American Society of Nuclear Cardiology; Heart Rhythm Society; Society of Cardiovascular Anesthesiologists; Society for Cardiovascular Angiography and Interventions; Society for Vascular Medicine and Biology; Society for Vascular Surgery. ACC/ AHA 2007 guidelines on perioperative cardiovascular evaluation and care for noncardiac surgery: a report of the American College of Cardiology/American Heart Association Task Force on Practice Guidelines (Writing Committee to Revise the 2002 Guidelines on Perioperative Cardiovascular Evaluation for Noncardiac Surgery): developed in collaboration with the American Society of Echocardiography, American Society of Nuclear Cardiology, Heart Rhythm Society, Society of Cardiovascular Anesthesiologists, Society for Cardiovascular Angiography and Interventions, Society for Vascular Medicine and Biology, and Society for Vascular Surgery. Circulation 2007; 116: e418-e499.

252 Poldermans D, Bax JJ, Schouten O, et al. Dutch Echocardiographic Cardiac Risk Evaluation Applying Stress Echo Study Group. Should major vascular surgery be delayed because of preoperative cardiac testing in intermediate-risk patients receiving beta-blocker therapy with tight heart rate control? J Am Coll Cardiol 2006; 48: 964-969.

253 Poldermans D, Schouten O, Vidakovic R, et al. DECREASE Study Group. A clinical randomized trial to evaluate the safety of a noninvasive approach in high-risk patients undergoing major vascular surgery: the DECREASE-V Pilot Study. J Am Coll Cardiol 2007; 49: 1763-1769.

254 McFalls EO, Ward HB, Moritz TE, et al. Coronary-artery revascularization before elective major vascular surgery. N Engl J Med 2004; 351: 2795-2804.

255 British Thoracic Society. Society of Cardiothoracic Surgeons of Great Britain and Ireland Working Party. BTS guidelines: guidelines on the selection of patients with lung cancer for surgery. Thorax 2001; 56: 89-108.

256 Colice GL, Shafazand S, Griffin JP, et al. American College of Chest Physicians. Physiologic evaluation of the patient with lung cancer being considered for resectional surgery: ACCP evidence-based clinical practice guidelines (2nd edition). Chest 2007; 132: 161S-177S.

257 Mandra A, Simić D, Stevanović V, et al. Preoperative considerations for patients with chronic obstructive pulmonary disease. Acta Chir Iugosl 2011; 58: 71-75.

258 Brunelli A, Refai M, Xiumé F, et al. Performance at symptom-limited stair-climbing test is associated with increased cardiopulmonary complications, mortality, and costs after major lung resection. Ann Thorac Surg 2008; 86: 240-247.

259 Win $\mathrm{T}$, Tasker $\mathrm{AD}$, Groves $\mathrm{AM}$, et al. Ventilation-perfusion scintigraphy to predict postoperative pulmonary function in lung cancer patients undergoing pneumonectomy. AJR Am J Roentgenol 2006; 187: 1260-1265.

260 Ferguson MK, Little L, Rizzo L, et al. Diffusing capacity predicts morbidity and mortality after pulmonary resection. J Thorac Cardiovasc Surg 1988; 96: 894-900.

261 Wang JS. Relationship of predicted postoperative product to postpneumonectomy cardiopulmonary complications. J Chin Med Assoc 2003; 66: 643-654.

262 Wang JS. Relationship of carbon monoxide pulmonary diffusing capacity to postoperative cardiopulmonary complications in patients undergoing pneumonectomy. Kaohsiung J Med Sci 2003; 19: 437-446.

263 Bolliger CT, Jordan P, Solèr M, et al. Exercise capacity as a predictor of postoperative complications in lung resection candidates. Am J Respir Crit Care Med 1995; 151: 1472-1480.

264 Holden DA, Rice TW, Stelmach K, et al. Exercise testing, 6-min walk, and stair climb in the evaluation of patients at high risk for pulmonary resection. Chest 1992; 102: 1774-1779.

265 Markos J, Mullan BP, Hillman DR, et al. Preoperative assessment as a predictor of mortality and morbidity after lung resection. Am Rev Respir Dis 1989; 139: 902-910.

266 Pierce RJ, Copland JM, Sharpe K, et al. Preoperative risk evaluation for lung cancer resection: predicted postoperative product as a predictor of surgical mortality. Am J Respir Crit Care Med 1994; 150: 947-955.

267 Nakahara K, Monden Y, Ohno K, et al. A method for predicting postoperative lung function and its relation to postoperative complications in patients with lung cancer. Ann Thorac Surg 1985; 39: 260-265.

268 Nakahara K, Ohno K, Hashimoto J, et al. Prediction of postoperative respiratory failure in patients undergoing lung resection for lung cancer. Ann Thorac Surg 1988; 46: 549-552.

269 Taylor MD, LaPar DJ, Isbell JM, et al. Marginal pulmonary function should not preclude lobectomy in selected patients with non-small cell lung cancer. J Thorac Cardiovasc Surg 2014; 147: 738-744.

270 Brunelli A, Al Refai M, Monteverde M, et al. Predictors of early morbidity after major lung resection in patients with and without airflow limitation. Ann Thorac Surg 2002; 74: 999-1003.

271 Edvardsen A, Akerø A, Hardie JA, et al. High prevalence of respiratory symptoms during air travel in patients with COPD. Respir Med 2011; 105: 50-56.

272 Ahmedzai S, Balfour-Lynn IM, Bewick T, et al. British Thoracic Society Standards of Care Committee. Managing passengers with stable respiratory disease planning air travel: British Thoracic Society recommendations. Thorax 2011; 66: i1-i30.

273 Seccombe LM, Peters MJ. Oxygen supplementation for chronic obstructive pulmonary disease patients during air travel. Curr Opin Pulm Med 2006; 12: 140-144.

274 Akerø A, Christensen CC, Edvardsen A, et al. Pulse oximetry in the preflight evaluation of patients with chronic obstructive pulmonary disease. Aviat Space Environ Med 2008; 79: 518-524.

275 Akerø A, Edvardsen A, Christensen CC, et al. COPD and air travel: oxygen equipment and preflight titration of supplemental oxygen. Chest 2011; 140: 84-90.

276 Abdool-Gaffar MS, Ambaram A, Ainslie GM, et al. COPD Working Group. Guideline for the management of chronic obstructive pulmonary disease-2011 update. S Afr Med J 2011; 101: 63-73.

277 Christensen CC, Ryg MS, Edvardsen A, et al. Relationship between exercise desaturation and pulmonary haemodynamics in COPD patients. Eur Respir J 2004; 24: 580-586. 